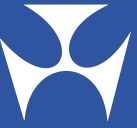

Reserve Bank of Australia

\section{RESEARCH \\ DISCUSSION \\ PAPER}

\section{Urban Structure and Housing Prices: Some Evidence from Australian Cities}

Mariano Kulish, Anthony Richards and Christian Gillitzer

RDP 2011-03 


\title{
URBAN STRUCTURE AND HOUSING PRICES: SOME EVIDENCE FROM AUSTRALIAN CITIES
}

Mariano Kulish, Anthony Richards and Christian Gillitzer

\author{
Research Discussion Paper \\ 2011-03
}

September 2011

Economic Group

Reserve Bank of Australia

We thank Peter Abelson, Dan Andrews, Arthur Grimes, Phil Manners, Glenn Otto, Judy Yates, and a number of colleagues, including Jonathan Kearns, Luci Ellis and Peter Tulip, for comments. The views expressed here are our own and do not necessarily reflect those of the Reserve Bank of Australia.

Authors: kulishm and richardsa at domain rba.gov.au

Media Office: rbainfo@rba.gov.au 


\begin{abstract}
This paper studies determinants of some aspects of the structure of cities, including density and the price of land and housing. We use a version of the Alonso-Muth-Mills model, calibrated to broadly match some of the features of a representative large city. While the calibrated model omits many real-world features, it can nonetheless be used to explore the impact of factors such as: (i) the provision of transport infrastructure; (ii) zoning policies that limit housing density; (iii) frictions on the production of housing; and (iv) population size. The empirical section of the paper shows that the model is consistent with some empirical regularities for large Australian cities. The results of the paper draw attention to structural factors that may have contributed to developments in the Australian housing market in recent years.
\end{abstract}

JEL Classification Numbers: R00, R52, R58

Keywords: housing, housing prices, land prices, zoning, land use 


\section{Table of Contents}

$\begin{array}{ll}\text { 1. Introduction } & 1\end{array}$

2. The Alonso-Muth-Mills Model 3

2.1 The Basic Model 3

2.2 Parameterisation of the Model 5

3. Determinants of the Urban Structure $\quad 7$

3.1 Transport Costs 8

3.2 Density Restrictions 10

3.3 Frictions on Housing Production 13

$\begin{array}{lll}3.4 & \text { Population Growth } & 15\end{array}$

4. Empirical Evidence 18

4.1 Housing and Land Prices 18

4.2 Housing Density 23

4.3 Land Use Policies 28

5. Conclusion 32

Appendix A: Model Calibration $\quad 35$

$\begin{array}{ll}\text { References } & 39\end{array}$ 


\title{
URBAN STRUCTURE AND HOUSING PRICES: SOME EVIDENCE FROM AUSTRALIAN CITIES
}

\author{
Mariano Kulish, Anthony Richards and Christian Gillitzer
}

\section{Introduction}

Housing prices in Australia have grown significantly in real terms and relative to household incomes over recent decades. Changes in housing prices, like changes in other prices, are the result of many underlying forces. There have been a number of important demand-side factors, most importantly the lower average level of nominal interest rates in the inflation-targeting period and the greater availability of credit stemming from financial deregulation (see e.g. Battellino (2009), Ellis (2006) and Richards (2008)). However, supply-side factors can also matter. It is noteworthy that while prices have risen significantly over an extended period and population growth has been quite strong, there has been no pick-up in the supply of new housing (see Figure 1). Indeed, the growth rate of the nationwide housing stock has been falling gradually over the past several decades, and in 2009 and 2010 was lower than at any time in at least the last 50 years. The corollary of the developments in housing supply is that average household size (the number of people per household) has risen in recent years, after declining gradually for at least a century.

This paper studies how some aspects of the supply and demand for housing determine the structure of cities, including density and the price of land and housing. In particular, we study the impact of the provision of transport infrastructure, land use policies such as zoning limits on housing density, and frictions that increase the cost of new housing development. We use a version of the Alonso-Muth-Mills model, calibrated to match broad features of a representative large city, to analyse the impact of these factors on the equilibrium structure of a city, the housing choices of households and the price of housing. We also examine how the equilibrium is affected by the size of the population, and in doing so show how certain policies that might initially have had only small effects could be expected to have large effects following significant growth in the population. 
Figure 1: Dwelling and Population Growth

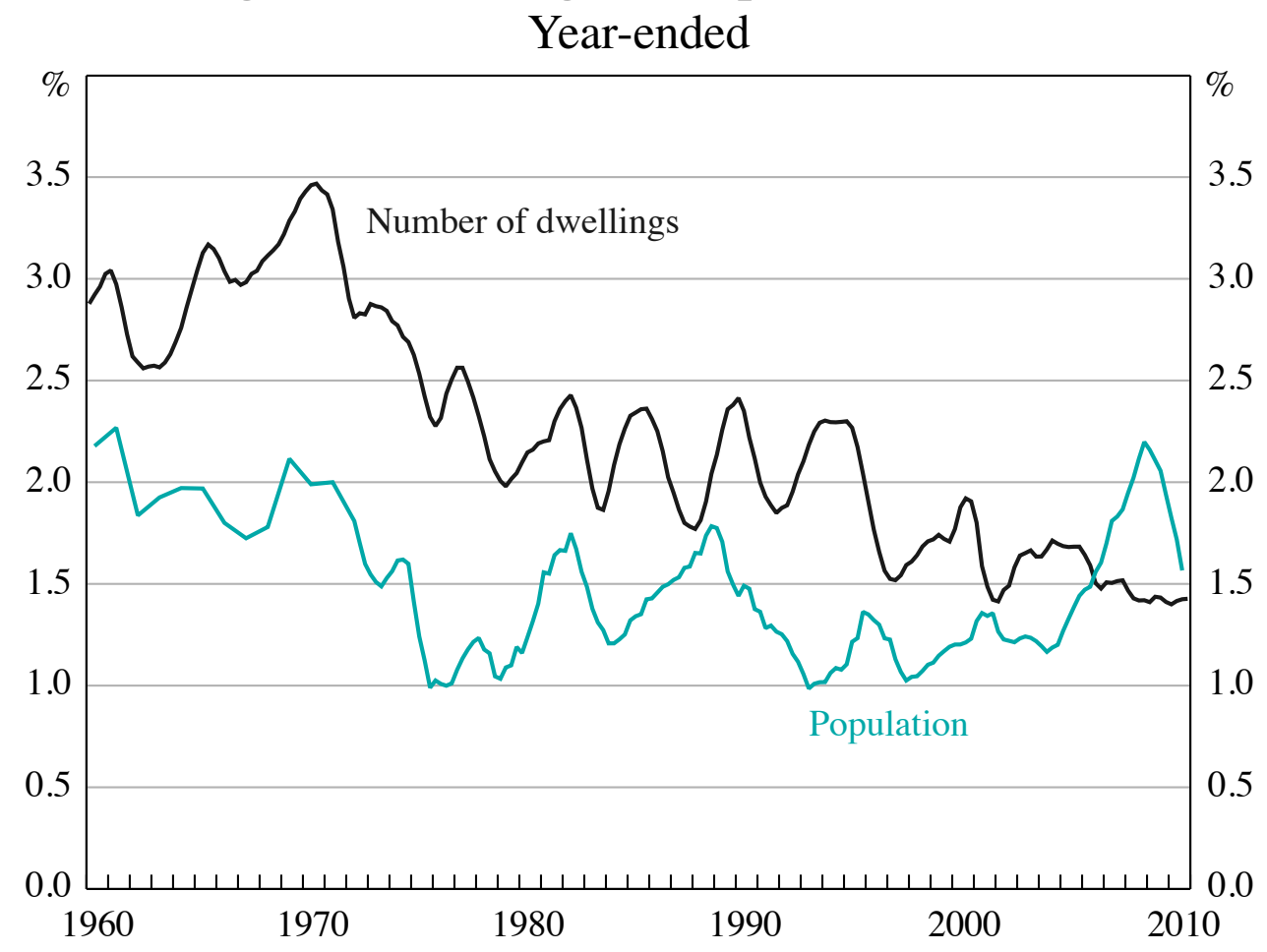

Notes: Population data annual until June 1972, quarterly thereafter. Number of dwellings estimated since 2006 Census and interpolated between earlier censuses, based on completions data.

Sources: ABS; RBA

Overall, the theoretical results draw attention to factors that are likely to have been contributing to developments in the Australian housing market over the past decade or more. Many observers, including in the development industry, have pointed to difficulties in the construction of medium- and high-density housing close to the CBD. In the context of the model, this would be consistent with a range of factors, including a shortage of appropriately zoned land, driving up development costs. Towards the city fringe, these factors could also be weighing on the economics of new construction, with poor transport infrastructure also affecting households' willingness to buy at more distant locations. Together, to the extent that these factors have driven up the cost of new housing and reduced its supply, they could be expected to have also increased the price of the existing stock of housing.

The paper is organised as follows. The next section lays out a basic version of the Alonso-Muth-Mills model. Section 3 studies the role of some key determinants of the urban equilibrium in the context of this model. Section 4 provides some 
empirical evidence on the structure of the major Australian cities, including housing prices, urban density and zoning, and assesses how these relate to some predictions of the model. Section 5 concludes.

\section{The Alonso-Muth-Mills Model}

We use a version of the well-established model of Alonso (1964), Muth (1969) and Mills (1967), and formalised by Wheaton (1974), with its parameters set to match broad features of a stylised city. Our description of the model and of the results that follow is intentionally non-technical. The intuition is straightforward in most cases, but readers interested in the technical details of the model and its calibration are referred to Appendix A and the articles in the references.

\subsection{The Basic Model}

The basic Alonso-Muth-Mills model assumes a city with a fixed population and a given income level living around a central business district (CBD). ${ }^{1}$ Each worker travels into the city centre for work. Since commuting is costly and increases with distance from the $\mathrm{CBD}$, households would choose, other things equal, to live closer to the city centre. But not everyone can live close to the city centre, so the price and density of housing adjust to clear the market. In particular, land for housing becomes more expensive closer to the CBD, which prompts homebuilders to economise on the use of land by building more dwellings per unit of land, that is by building multi-storey buildings and smaller dwellings, as the cost of an additional square metre rises with building height. Households then choose whether to live in well-located, but smaller and more expensive, housing or in more distant, but larger and less expensive, housing towards the city fringe. The city structure is characterised by higher density and taller buildings close to the CBD and lower density and building heights on the fringe. The overall size of the city will be determined simultaneously by the size of the population, the cost of transport and the value of land in alternative uses, such as agriculture.

1 We discuss the 'closed-city' version of the model which takes the population as exogenous. An 'open-city' version allows for migration flows, in which case the city's population is determined endogenously. See also Brueckner (1987) and Anas, Arnott and Small (1998) for survey articles on the model and various extensions. 
The model, like all models, simplifies a more complex reality and has limitations. Some of the simplifications are as follows. First, individuals are assumed to be identical in terms of income and preferences. It is, of course, self-evident that real-world cities are characterised by heterogeneity in incomes and housing, but the basic insights of the model remain even in models that allow for these kinds of heterogeneity (e.g. Anas (1990)). While households' preferences for housing are summarised by their demand for generic 'housing', other versions of the model have explicitly included demand for yard space (e.g. Arnott and MacKinnon (1977) and Brueckner (1983)), and the qualitative conclusions of our analysis would be similar with such an extension.

Second, the city is assumed to be monocentric, with individuals travelling only to go to work in a central location. Accordingly, the model does not allow for other business districts within the city (that is, for a polycentric city), or for locations to be considered desirable based on other attributes like proximity to education facilities or leisure activities (such as cultural facilities, beaches, etc). Such attributes, as we show in the case of waterfront suburbs in Section 4, can be important in real-world cities. But the conclusions from the basic model are qualitatively robust to such extensions: see, for example, Henderson and Mitra (1996) for an analysis of a model with multiple employment centres.

Third, the equilibrium is partial, in the sense that it abstracts from developments in other markets, like the labour or capital markets. So, the wage rate and the rental rate on capital are taken as exogenous.

Finally, the model is static and asks what would be the equilibrium structure for a city given certain assumptions. That is, it does not account for the long-lived nature of the housing stock, nor the process of urban change and phenomena such as filtering or gentrification, nor the role of changes in the availability of finance. Instead, the model is best viewed as providing insights into the longer-run determinants of the urban equilibrium.

The model's simplicity helps focus on fundamental forces, likely to matter for all large cities. Indeed, as Brueckner (1987) argues, this simple yet powerful model explains the main observed regularities of the urban structure - including, as will be seen in Section 4, many of the stylised facts of Australian cities. ${ }^{2}$ Furthermore,

2 See Spivey (2008) for a recent test of the model using data for US cities. 
the model is well suited for the purposes of this paper: namely to understand the impact that different policies and population growth have on the characteristics of the urban equilibrium.

\subsection{Parameterisation of the Model}

To illustrate the forces that determine the structure of the city in the model, we select parameter values, drawing on the work of Bertaud and Brueckner (2005). In broad terms, we match some characteristics of a large Australian city. In particular, we consider a city with two million residents, who live around a CBD. To match the geography of coastal cities and the need for roads and land for other purposes, we assume that housing construction is only possible in a little less than half of the circle around the centre. The price of land at the city fringe is equal to the cost when used in agriculture, and the price within the city is determined, among other factors, by building costs, transport costs, and household incomes and preferences. Households spend part of their income commuting to the CBD, with the cost rising with distance from the CBD: in calibrating transport costs, we account also for the time spent commuting and value it at 60 per cent of the wage rate. They spend the remainder of their income on housing and other goods, with Cobb-Douglas preferences, allocating around 15 per cent to housing. ${ }^{3}$ Firms use land and capital to build housing around the city, with the production function also Cobb-Douglas. Construction costs rise as additional stories are added, so per square metre costs are lower at the fringe than closer to the CBD.

The results of this benchmark parameterisation are shown in Figure 2, with distance from the CBD as the bottom axis of each panel. ${ }^{4}$ Based on households' preferences for proximity to the $\mathrm{CBD}$, land is priced more highly closer to the

3 This 15 per cent figure broadly matches the average for all households in the 2005/06 ABS Household Expenditure Survey; in reality, younger households spend a greater fraction than this average, while older households spend less.

4 As noted in the text, the parameterised model should not be expected to fit all dimensions of any particular city. The units of this figure and subsequent ones are as follows: housing (rental) prices in dollars per square metre of living space per year; dwelling size in square metres of living space; building height in housing floor space per unit of land, which corresponds roughly to stories; density in persons per square kilometre; (rental) price of land in thousands of dollars per hectare per year; and population in thousands. The model refers to the rental price of housing and land, but under an assumption of a given capitalisation rate, these translate directly to purchase prices, which we refer to in our discussion. 
city centre and declines as one moves further from the CBD (bottom left panel). Accordingly, building firms and households economise on the use of well-located land. As a result, building height is higher closer to the centre (middle left panel) and dwelling size is smaller (upper right panel). An implication is that population density rises sharply closer to the CBD (middle right panel). Housing prices (per unit of living space) are naturally also higher closer to the CBD (upper left panel), with lower housing prices and larger dwelling sizes providing the incentive for some households to live further from the CBD. Finally, the particular distance at which home-builders and households no longer value land more highly than agricultural users corresponds to the city boundary, around 35 kilometres in this calibration. Given the city population and density at different distances to the city, we calculate a curve (lower right panel) that shows, at every distance from the $\mathrm{CBD}$, the number of residents that reside up to that location.

\section{Figure 2: The Unconstrained Urban Equilibrium}

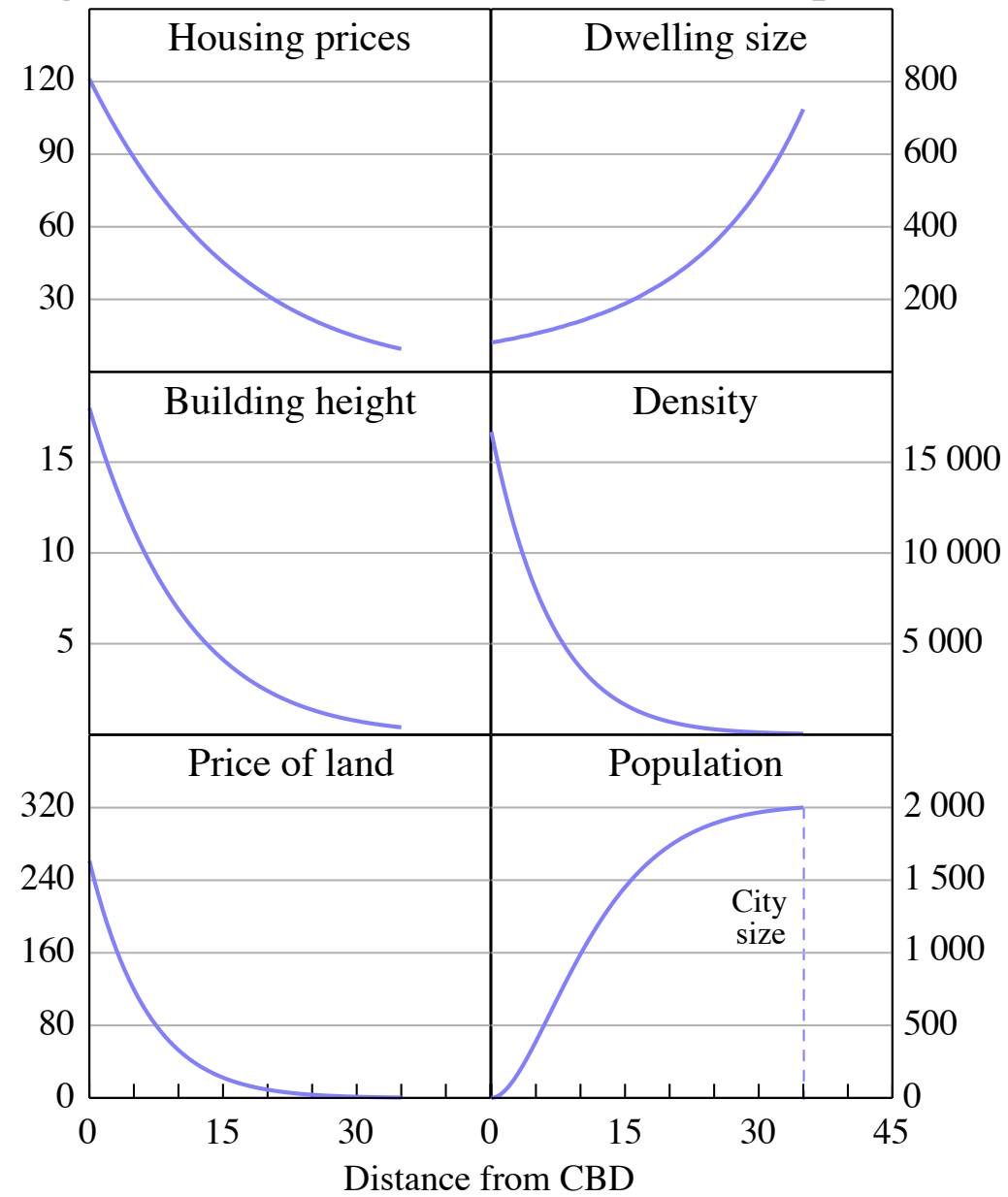

Note: Units are as outlined in footnote 4 
We take this parameterisation as a benchmark; it is not an attempt to fit particular features of the data. In the benchmark calibration, population density, for example, seems high close to the city centre: around half the population lives within ten kilometres of the centre, which is higher than is the case of the five largest Australian cities. Of course, if policies to limit density are binding in reality or if cities have multiple business centres, calibrating an unconstrained monocentric model will, not surprisingly, suggest higher density close to the city centre than is observed in reality. Similarly, given that real-world cities grow gradually and housing structures are long-lived, it should not be surprising if actual cities are geographically larger than the equilibrium suggested by a model which abstracts from these sort of adjustment costs. Having said this, we use this calibration as an initial benchmark against which to assess the impact of various policies and the impact of population growth.

\section{Determinants of the Urban Structure}

We now turn to analyse the impact that choices about transport infrastructure, zoning and development policies, and population size have on the structure of cities. Following Newman, Kenworthy and Vintila (1992), one can consider the structure of a city as influenced by a number of factors including:

- the transport possibilities available for residents;

- policies with respect to development and infrastructure on the fringe;

- the priority given to the provision of space (or the avoidance of density) within the city; and

- the planning practices and institutions that affect the three foregoing factors.

We model these influences by changing aspects of the calibration described above. In particular, we discuss three types of public policies that affect housing market outcomes: (i) policies that impact on the efficiency of the transport infrastructure within the city, (ii) policies that limit housing density, and (iii) policies that increase the cost of building new housing. As is noted above, the model is a partial equilibrium one, which implies that the analysis cannot capture all the effects 
of such policies. While we expect that the results that we highlight are of firstorder importance for variables such as housing prices, we also discuss some of the associated trade-offs likely to be present in more real-world settings. In each case, it is also important to remember the static nature of the model, so that we are not specifically modelling the short-run effects of changes in such policies on an existing city. Rather, the exercises that follow could be thought of as comparing the long-run equilibrium structure of two otherwise identical cities, if they were to differ only in the application of a particular policy. ${ }^{5}$

\subsection{Transport Costs}

We first consider the impact of policies with respect to transport infrastructure. In particular, we contrast the urban structure of two cities, one where there has been significant investment in transport infrastructure - defined broadly to include both public transport and car-based road infrastructure - and the other where the transport infrastructure is less well developed and transport costs are higher as a result. We abstract from any issues relating to the financing of the transport infrastructure as they are beyond the scope of this paper. Considering these costs would, of course, reduce the net gains to households that come from improved transport infrastructure. ${ }^{6}$

In the calibration, we consider the effect of doubling transport costs, with the results shown in Figure 3. Because commuting is more costly, households have a stronger incentive to live closer to the CBD, and the city size is significantly smaller as a result (lower right panel), with the calibration suggesting a fall in the radius of the city from 35 kilometres to around 21 kilometres. To accommodate the denser population, building heights are higher close to the CBD (middle left) and dwelling sizes are smaller (upper right). Housing and land prices are also higher close to the CBD (upper and lower left panels). At greater distances from the CBD, several of the curves cross: with higher transport costs, it is more costly to live further out, so housing prices, land prices and density near the new city fringe (around 20 kilometres) are lower than at the same distance under low transport

5 Brueckner (2007) also discusses the effects of various forms of government land-use interventions.

6 However, see, for example, Centre for International Economics (2011) for a study that points to net economic benefits from seven proposed transport projects in the Sydney metropolitan area. 
costs. This is not to say, however, that any part of the population is better off. For example, if we were to rank households by distance from the CBD, then households at any distance percentile have a smaller home and face higher housing prices (per square metre) under higher transport costs than households at that same percentile under lower transport costs.

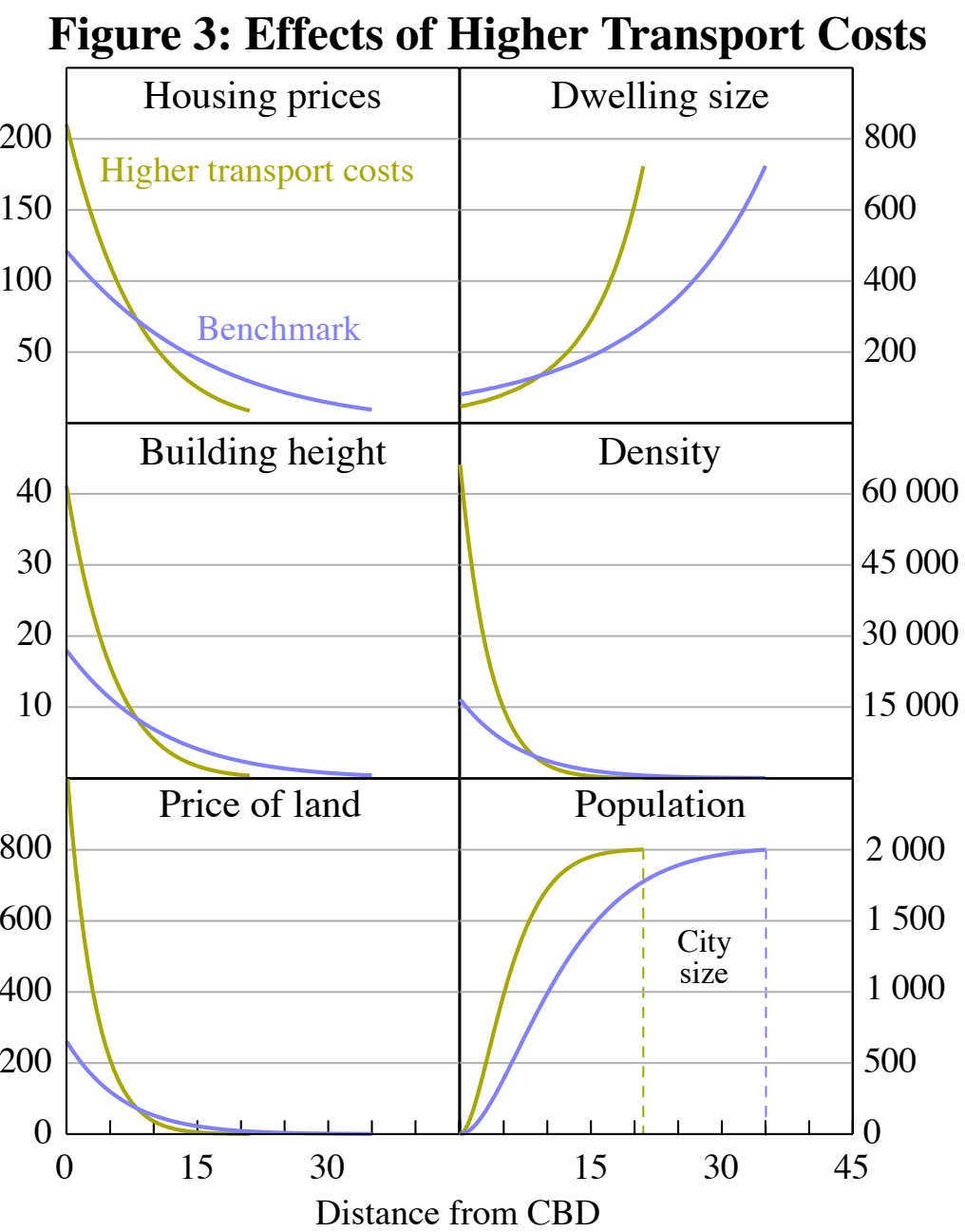

Note: $\quad$ Units are as outlined in footnote 4

Overall, the effect of poor transport infrastructure and higher transport costs is that households spend more of their resources commuting, live in smaller homes and face higher average housing and land prices. By contrast, the model suggests that well-directed investment in transport infrastructure makes it more feasible to live further from the CBD and can thereby reduce the cost of housing. 


\subsection{Density Restrictions}

Next, we consider the effect of zoning policies that reduce the density that would result in an unconstrained case. In practice, there are a wide range of restrictions placed on the usage of land for housing, in many cases to limit the density of housing. These include zoning rules that allow only relatively low density uses for particular areas or blocks, or subdivision rules that set minimum limits on lot sizes or street frontages. For the current exercise, we consider a situation where zoning rules limit the density of housing by imposing an across-the-city restriction on the floor-to-area ratio (FAR) of buildings, that is a restriction on the total amount of floor space that can be produced on any unit of land. While in the model all buildings at a given distance from the CBD are identical in height, the FAR that we impose can be thought of as a restriction on average building height in any neighbourhood. Thus our analysis can be viewed as consistent with a range of types of density restrictions, including real-world examples where some land in a suburb can be used for higher-density housing and other land is zoned to only permit single-family houses. As in Bertaud and Brueckner (2005), we apply a FAR restriction that corresponds approximately to a limit (on average) of four stories in any area.

Figure 4 shows the impact on the equilibrium structure of a height restriction across the city. This type of zoning restriction constrains the supply of housing, with the restriction obviously most binding close to the CBD where building height would naturally be highest. Because a significant proportion of the city's population are unable to live in higher-density housing close to the the CBD, the population on average is 'forced outwards', overall city size is larger (bottom right panel), overall density is lower, and the population devotes more resources to commuting. The zoning restrictions force building height close to the CBD to be lower, but building height in the middle and outer suburbs is higher than it would otherwise be (middle left), to accommodate the people forced out from close to the CBD.

The price of housing is higher at all distances from the CBD (top left) because the supply of well-located housing has been reduced. As a result of the higher price of housing, dwelling size is lower at all distances from the CBD (top right). The effect on land prices, however, differs depending on distance from the CBD. Land prices are lower close to the CBD (bottom left), where density is much lower 
than in the unconstrained city (middle right), because developers cannot build as high and therefore accommodate as many people. But land prices and density are higher than they would otherwise be in the middle and outer rings, where there is increased demand for housing to accommodate those residents who are unable to live close to the CBD.

\section{Figure 4: Effects of a Building Height Restriction}

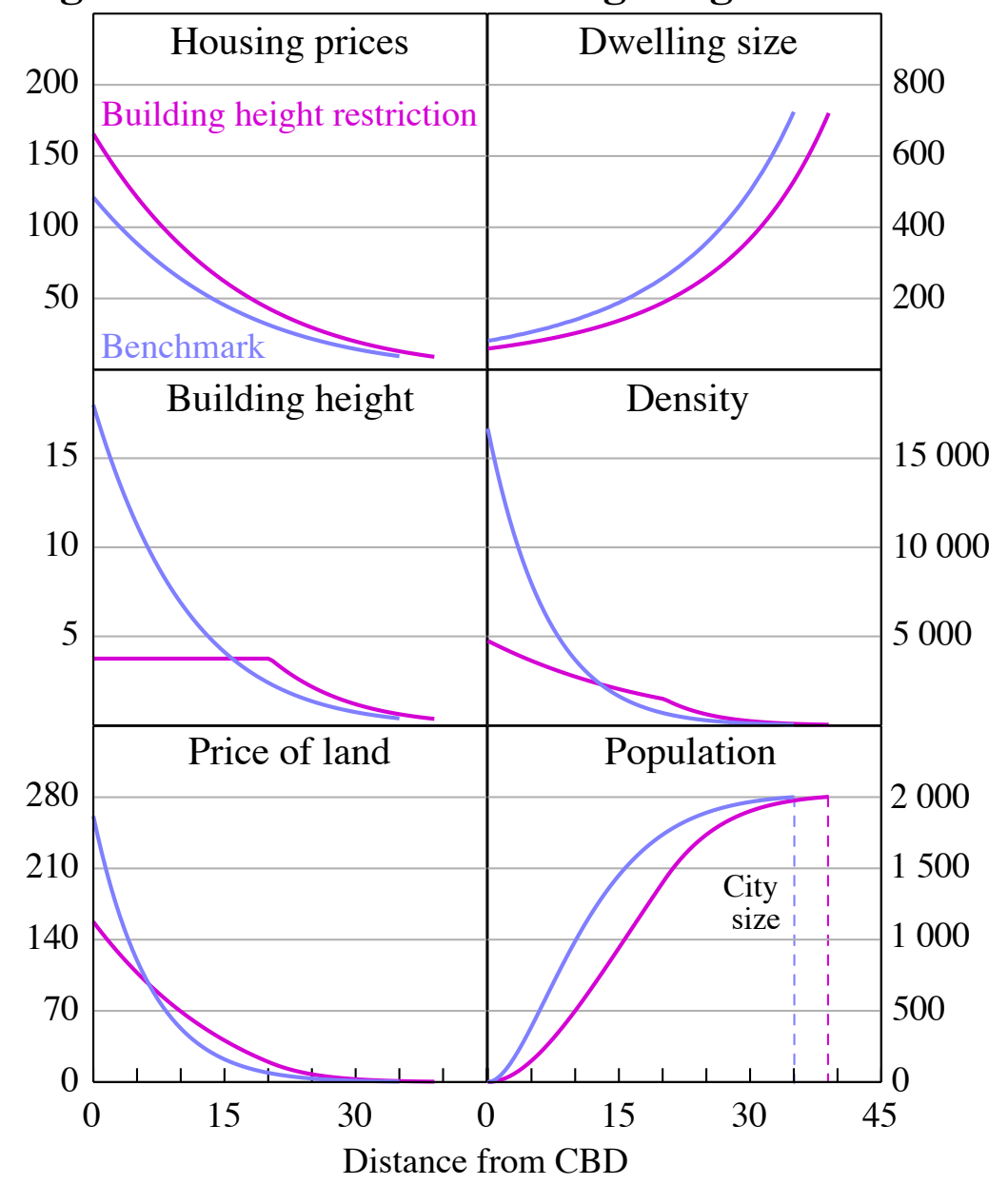

Note: $\quad$ Units are as outlined in footnote 4

While the model is not dynamic, Figure 4 points to the type of adjustment that could be expected over time if there were to be a significant city-wide easing in zoning restrictions. While the cost of housing could be expected to fall across the city, the price of land close to the CBD would be expected to rise, given that more housing can now be built on that land.

In addition, the calibrated model also allows us to compute, for any distance from the $\mathrm{CBD}$, what the value of a single block of land would be if the zoning restriction did not apply solely for that block. Figure 5 adds one curve to the lower left panel 
of Figure 4. This curve shows the value of a block of land at each distance from the $\mathrm{CBD}$, assuming that the height restriction did not apply for that block. The difference, as one would expect, is larger closer to the CBD. Indeed, whereas the absence of the zoning restriction for all land implies land prices are about 66 per cent higher near the $\mathrm{CBD}$, in the absence of the restriction for just a single block near the CBD the land value is around 260 per cent higher. The differential between these scenarios gradually declines as one moves outwards, and there is no difference where the zoning restriction no longer binds.

\section{Figure 5: Effects of Alternative Zoning Assumption on Price of Land}

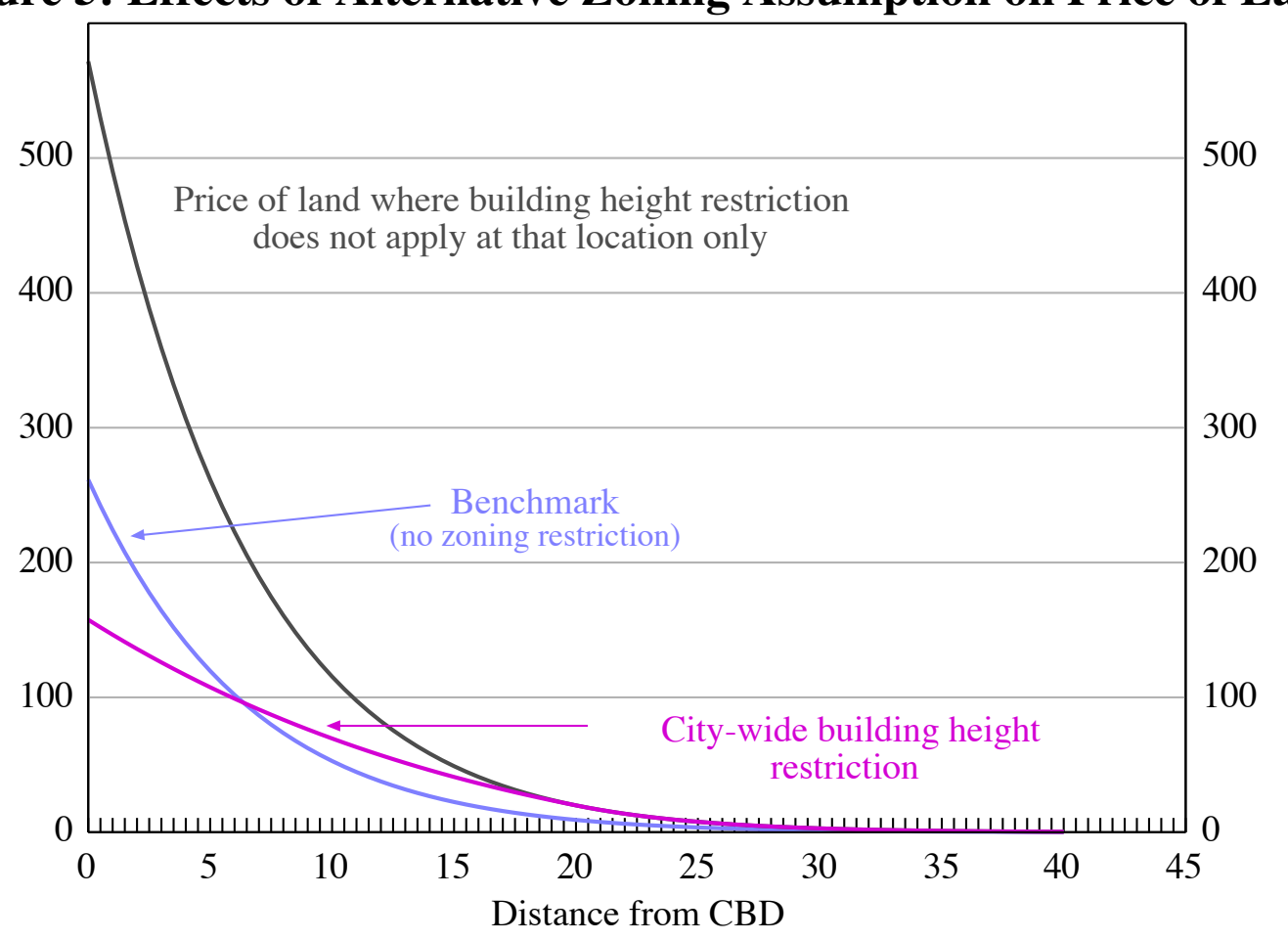

Note: Units are as outlined in footnote 4

The large difference in the value of the land close to the CBD highlights the potentially significant incentives for landowners to seek 'spot' rezonings in circumstances where zoning laws are strongly binding. For example, Evans (1999), in discussing the case of the United Kingdom, notes that 'because planning permission is worth acquiring, it has been worth spending money and resources to acquire it. So ... developers have often incurred substantial sums of "rent seeking expenditure" to try to persuade local planning authorities and the central government, if necessary, that planning permission should be given'. Indeed, Glaeser, Gyourko and Saks (2005a) set up a theoretical model 
where spending by developers and existing town residents are factors influencing decisions on land development by the relevant zoning body.

While the preceding results focus on the costs of binding zoning restrictions, in terms of higher housing prices resulting from reduced supply of housing, there are, of course, also benefits associated with well-designed zoning. For example, there are benefits from separating housing and industrial activity, and preserving green space within cities. More generally, there are a range of trade-offs associated with zoning policies. Our analysis highlights the effect on housing prices of reducing the supply of housing. Of course, policies to limit density may reflect other preferences of the existing population - which the model abstracts from such as a preference to live 'less densely'. However, the analysis highlights an important point: there is an unavoidable trade-off between density and housing prices. $^{7}$

\subsection{Frictions on Housing Production}

We now consider the effect of other policies that increase the cost of housing supply. More specifically, we model the effect of frictions that create a wedge between the purchase price (the price consumers pay for housing) and the price that producers receive.

This exercise is an attempt to capture the effect of various cost-increasing factors cited by a range of Australian observers (e.g. Applied Economics (2010), Chapter 4 of Caplin et al (2003), Gurran, Ruming and Randolph (2009) and Productivity Commission (2011)). These factors include long and uncertain planning processes involving multiple state and local authorities, costs associated with structuring new developments to comply with various requirements, infrastructure charges associated with new developments (either within the city or at the fringe) that are in excess of any benefits developers or homebuyers may receive, and the interest costs associated with lengthy delays in the development process. ${ }^{8}$

7 See Evans (2004) for a broader discussion of economic issues surrounding zoning and other land-use controls and Gurran (2007) for a discussion of the procedural aspects of the planning process in Australia.

8 To illustrate the potential for the planning process to have a significant impact on the economics of development, we note that one state agency showed us a Gantt chart that showed more than 500 required steps that developers faced in the various phases of the planning process. 
Of course, any development process will involve steps which have associated costs and benefits. For example, while meeting environmental standards represents a cost to developers and homebuyers, these standards also result in private and social benefits. The model does not capture any such benefits. Instead, the frictions that we model can be viewed as capturing the extent to which costs to developers exceed any associated benefits they or homebuyers may receive.

Figure 6 illustrates the impact of frictions in the production of housing, such that there is a wedge that lifts the selling price by 25 per cent above the cost of supply. In the city with frictions in production, consumers pay a higher price than otherwise at all locations (upper left panel). As a result people live in smaller dwellings (upper right). As these frictions make it less profitable to produce and sell housing, housing supply and building height fall at all locations (middle left). With housing development less profitable and less demand for housing, the price of land falls at all locations (bottom left). There is a small reduction in the size of the city, but overall population density is broadly unchanged with effects of dwelling sizes and building heights broadly offsetting (middle and lower right). With households facing higher prices and living in smaller dwellings, they are worse off as a result of the frictions in housing production. ${ }^{9}$

9 As noted above, the analysis uses the 'closed-city' version of the model where the population is fixed. Alternatively, our analysis can be thought of as capturing the situation where the policies that we model apply to all cities within an economy (and external migration is small). In an 'open-city' case, where households have the choice of living in other cities not subject to such policies, we would expect smaller adverse effects on prices and dwelling size. Aura and Davidoff (2008) model this effect, showing that loosening supply-side constraints in one jurisdiction may have little effect on prices, but a co-ordinated easing across markets may have large effects. 


\section{Figure 6: Effects of Frictions in Housing Production}

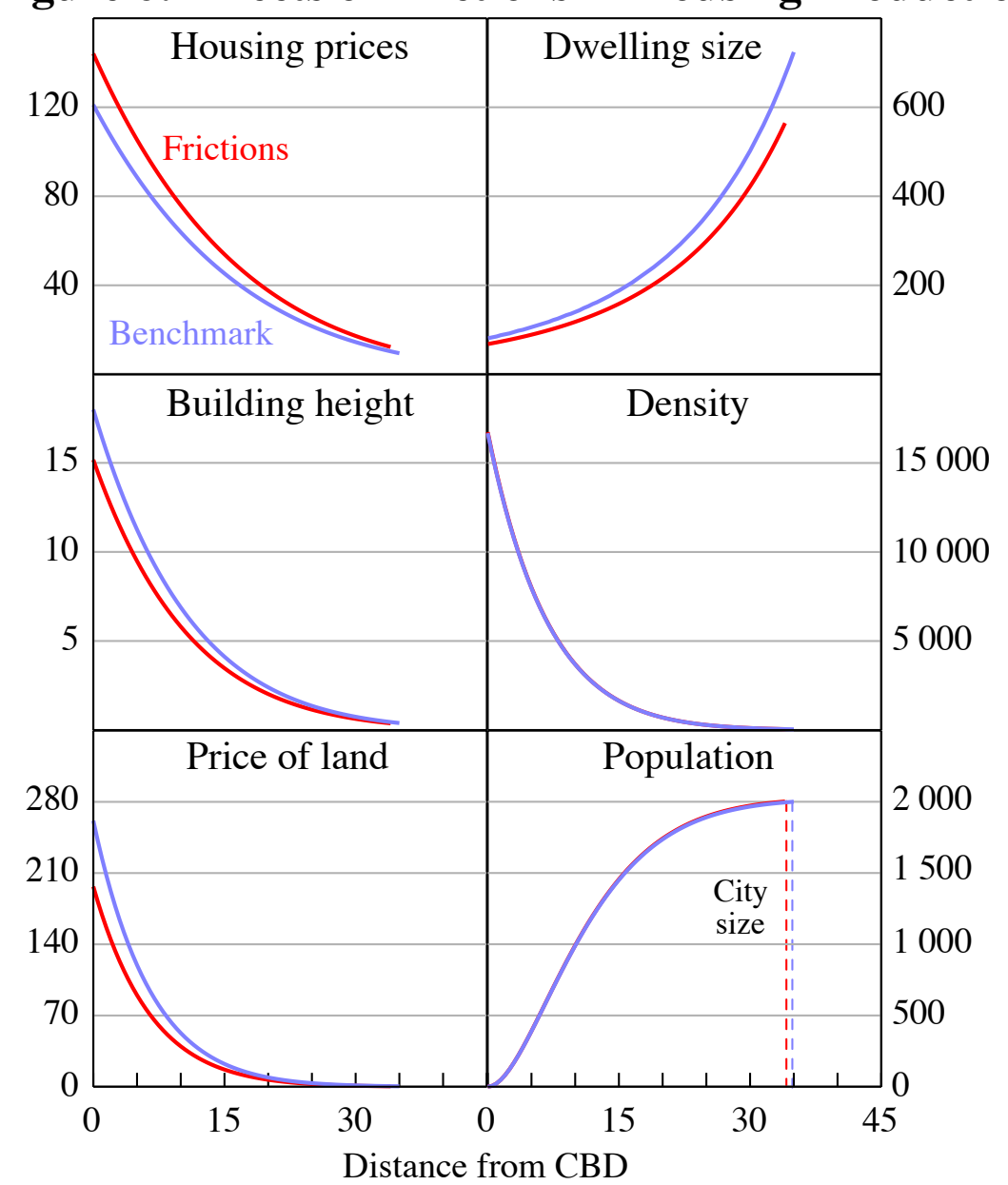

Note: Units are as outlined in footnote 4

\subsection{Population Growth}

How would an unconstrained city adjust to a larger population? The model is static and therefore cannot capture the dynamics associated with urban change. It is nevertheless useful for a comparative analysis of different longer-run urban equilibria. In particular, the model allows us to compare the equilibrium structure of two cities with otherwise similar characteristics (incomes, preferences, housing production technology, transport costs, etc) but differing in population. In Figure 7 we compare the equilibria of two cities with populations of two and four million people.

Not surprisingly, with greater demand for housing, housing and land prices are higher at all locations in the city with a larger population (upper and lower left panels). Because of higher housing prices, households demand smaller dwellings 


\section{Figure 7: Effect of Larger Population on Urban Structure}

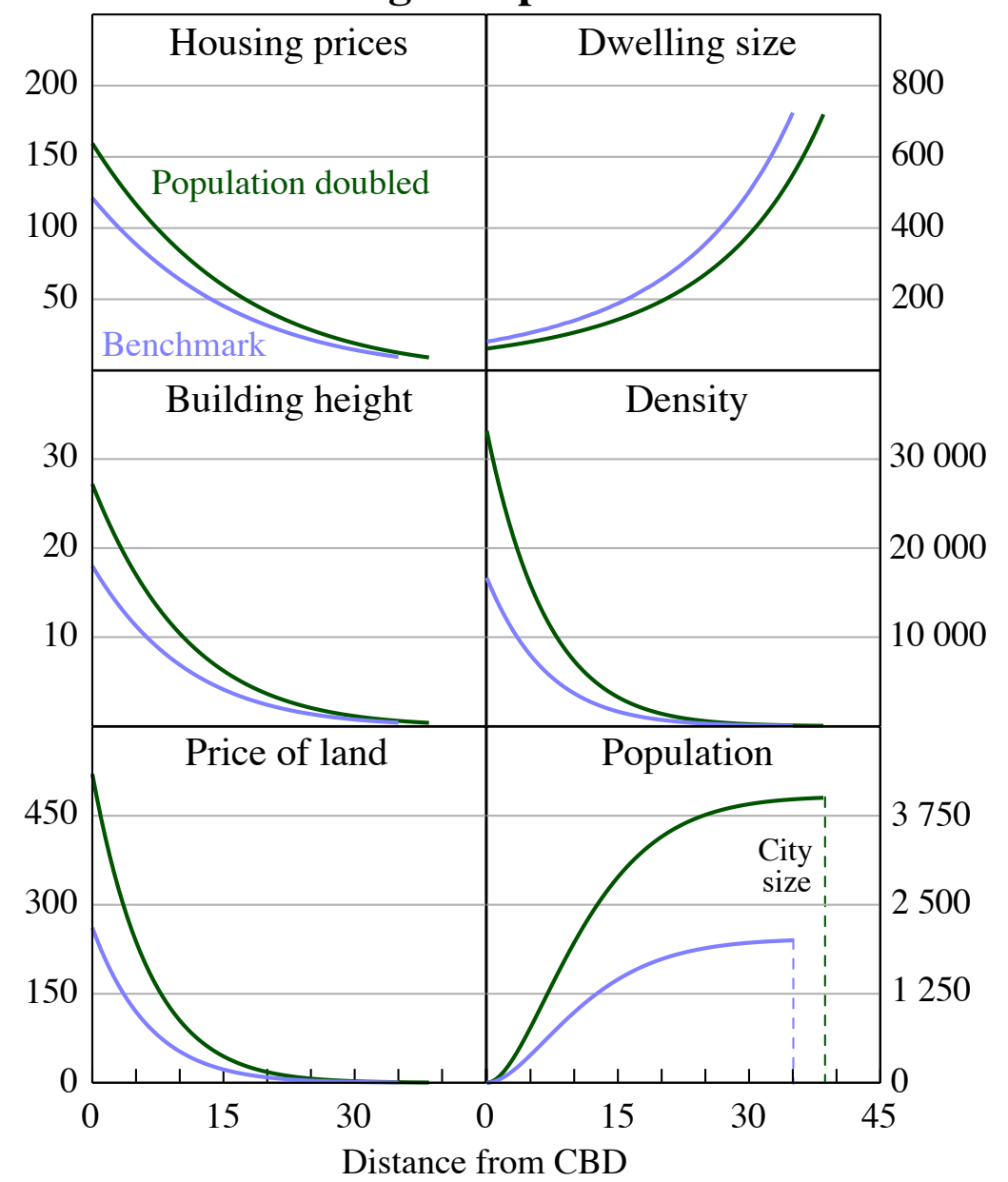

Note: Units are as outlined in footnote 4

(upper right) and population density is higher (middle right). Building height rises at all distances from the CBD (middle left). The larger population results in the city occupying a larger area (lower right).

However, the increase in city size implied by our calibration is arguably quite small, with the radius of the city rising by only 9 per cent (from around 35 to 38 kilometres) and the area rising by 18 per cent, despite a doubling of the population. The reason is the increase in building heights and the reduction in dwelling sizes. Indeed, although there are two million more individuals in the larger city, only around 1 per cent of these live further from the CBD than the edge of the smaller city. In this light, the metropolitan strategies for the large 
Australian cities that target 50-70 per cent of population growth occurring in infill housing rather in greenfield housing might not seem unreasonable. ${ }^{10}$

We can also use the model to consider how a city constrained by zoning policies would adjust to a growing population. As before, the zoning restriction we consider is a FAR that limits building heights to around four stories. Figure 8 compares the equilibrium housing price (per square metre of housing) at $10 \mathrm{~km}$ from the CBD for different populations from 250000 to four million, for two cases: that of an unconstrained city and that of a city with a zoning restriction like a FAR. For small populations there is almost no difference in housing prices because zoning restrictions are not really binding at 10 kilometres from the city. For larger populations, there is a gradually larger impact because zoning restrictions prevent the natural tendency towards higher buildings.

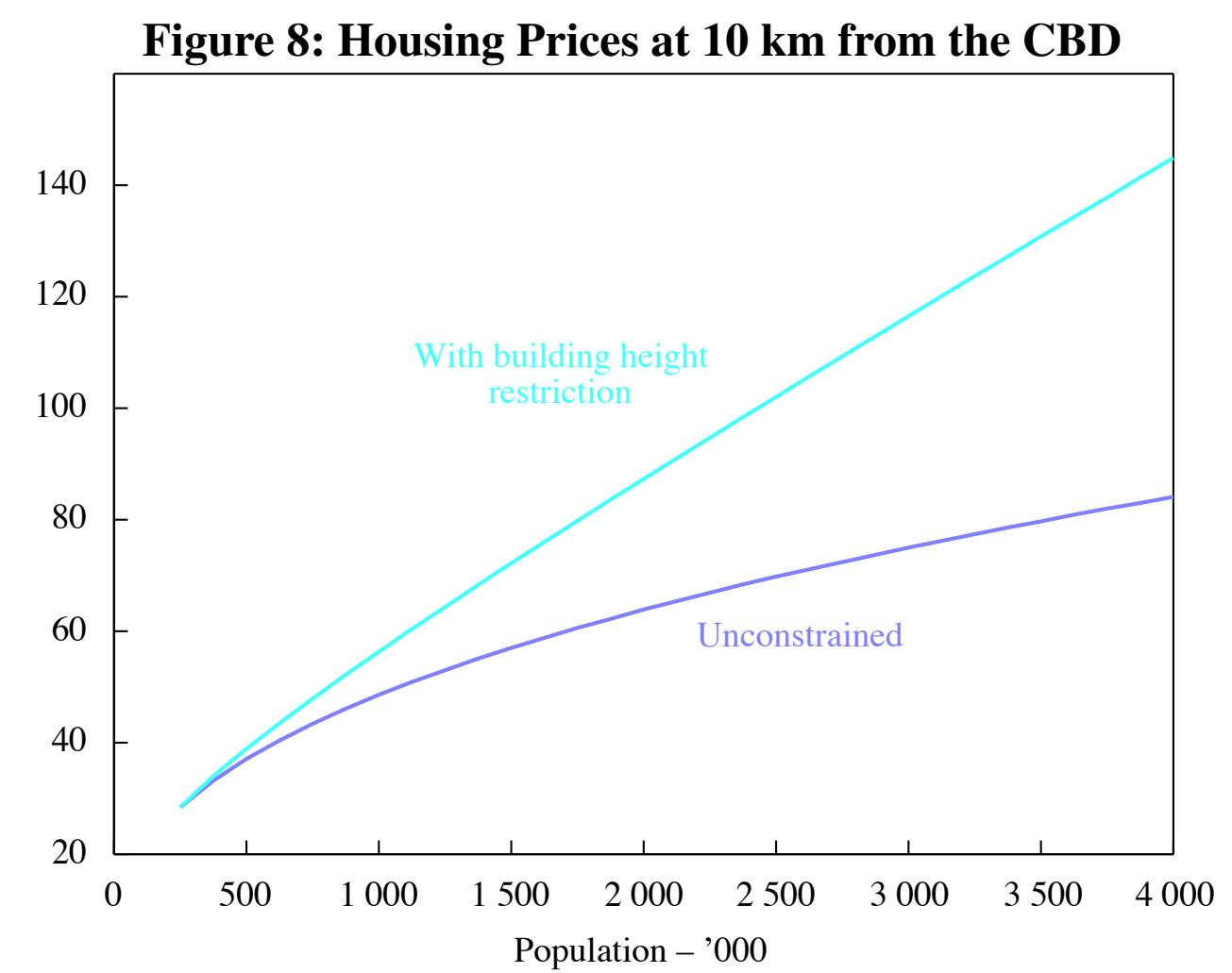

Notes: Units are as outlined in footnote 4; up to a level effect the curves are the same at any distance from the CBD

10 Of course, the results from our calibration should be viewed as applying to cities that could costlessly adjust to accommodate a higher population and increase in density. A model that allowed for path dependence, especially the sunk costs associated with existing housing and infrastructure, would no doubt indicate more population growth would occur at the fringe. 
To get a further sense of the magnitudes involved, we consider the impact on housing prices of relaxing the zoning restriction. In particular, we increase the maximum FAR by one story. We find, for a population size of two million, that an extra story, by allowing increased housing supply closer to the CBD, leads to housing prices that are around 10 per cent lower. However, for a population of four million, allowing buildings to be higher by an extra story results in housing prices that are around 13 per cent lower. That is, with zoning restrictions, population growth results in a larger increase in equilibrium housing prices than would be the case in an unconstrained city.

\section{Empirical Evidence}

\subsection{Housing and Land Prices}

There is relatively little published data on land prices in Australia's major cities, making it difficult to test some of the model's implications. One exception, however, is for Sydney where the NSW Land and Property Information (LPI) division publishes estimated land values for standard residential blocks in selected suburbs. Prices for 2010 are shown in Figure 9, converted into thousands of dollars per square metre, along with distance from the CBD. There is a clear tendency for higher values for land closer to the CBD, as illustrated by the fitted line based on a kernel density estimate. Indeed, the average land value for the five suburbs within 4 kilometres of the CBD in 2010 was around 16 times the average value for the six suburbs that are at least 50 kilometres from the CBD. This difference is consistent with the implications of the model, in which transport costs lead households to value proximity to the $\mathrm{CBD}$.

We can also examine the structure of housing prices within the five largest Australian cities using using postcode-level data. ${ }^{11}$ The analysis uses annual median prices for houses by financial year, subject to the requirement that there were more than ten transactions in a postcode in a year.

As is illustrated in Figure 10, house prices tend to be highest close to the centre of each city, consistent with the model's predictions about land and housing prices. Of course, distance from the $\mathrm{CBD}$ is not the only factor influencing the desirability

11 The data for housing prices and distance to the CBD were provided by RP Data-Rismark. 
Figure 9: Sydney Land Prices - 2010

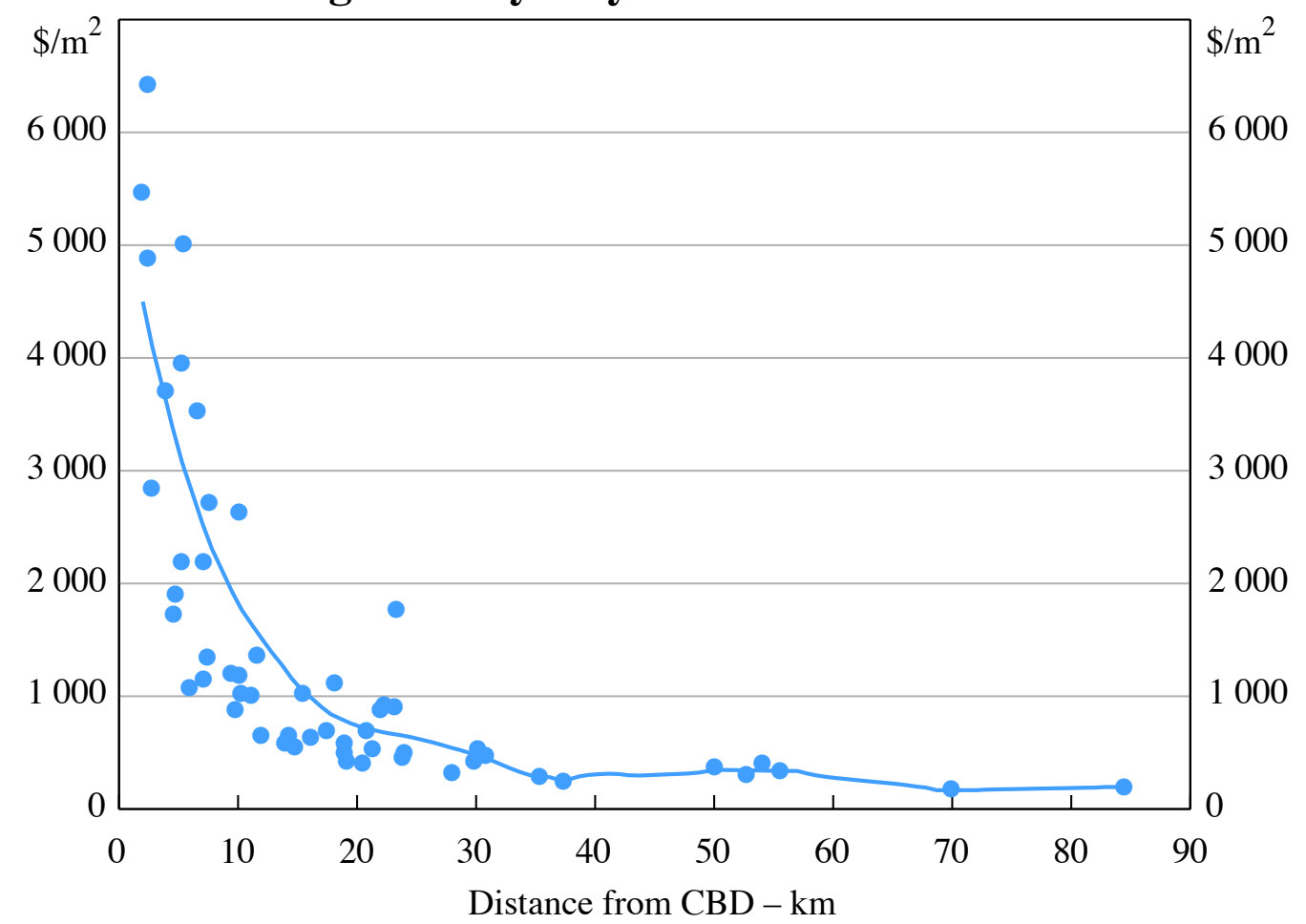

Source: authors' calculations based on data from Land and Property Information and RP DataRismark

of suburbs, and, consistent with Richards (2008), we find that house prices tend to be higher in waterfront suburbs. We illustrate the effect of proximity to the $\mathrm{CBD}$ and to the water in the city-level panels of Figure 10 by fitting regression lines with log prices in the five largest capitals as a function of distance to the CBD, the square of distance, and a dummy for waterfront suburbs. ${ }^{12}$ The adjusted $\mathrm{R}$-squareds indicate that distance to the CBD and water explain between 40 and 70 per cent of the variation in median prices in these five cities in 2009/10. The regressions indicate that the waterfront effect is largest (adding around 50 per cent to prices) in Sydney and Perth, and lowest in Brisbane and Adelaide. In results that are omitted to save space, we have found that proximity to the CBD and the water are also very significant in explaining the price of apartments in these five cities.

12 Waterfront postcodes are defined as those adjacent to the ocean or harbour, or on a river of significant width. For estimation of the fitted lines, we constrain the functional form so that house prices decline monotonically with distance from the CBD. This is a fairly basic example of a hedonic price model: see Hill and Melser (2007) for an example where price indices are estimated using individual sales data, and many more variables including distance to schools, public transport, etc. 
Figure 10: Postcode-level House Prices - 2009/10

Log scale, median prices

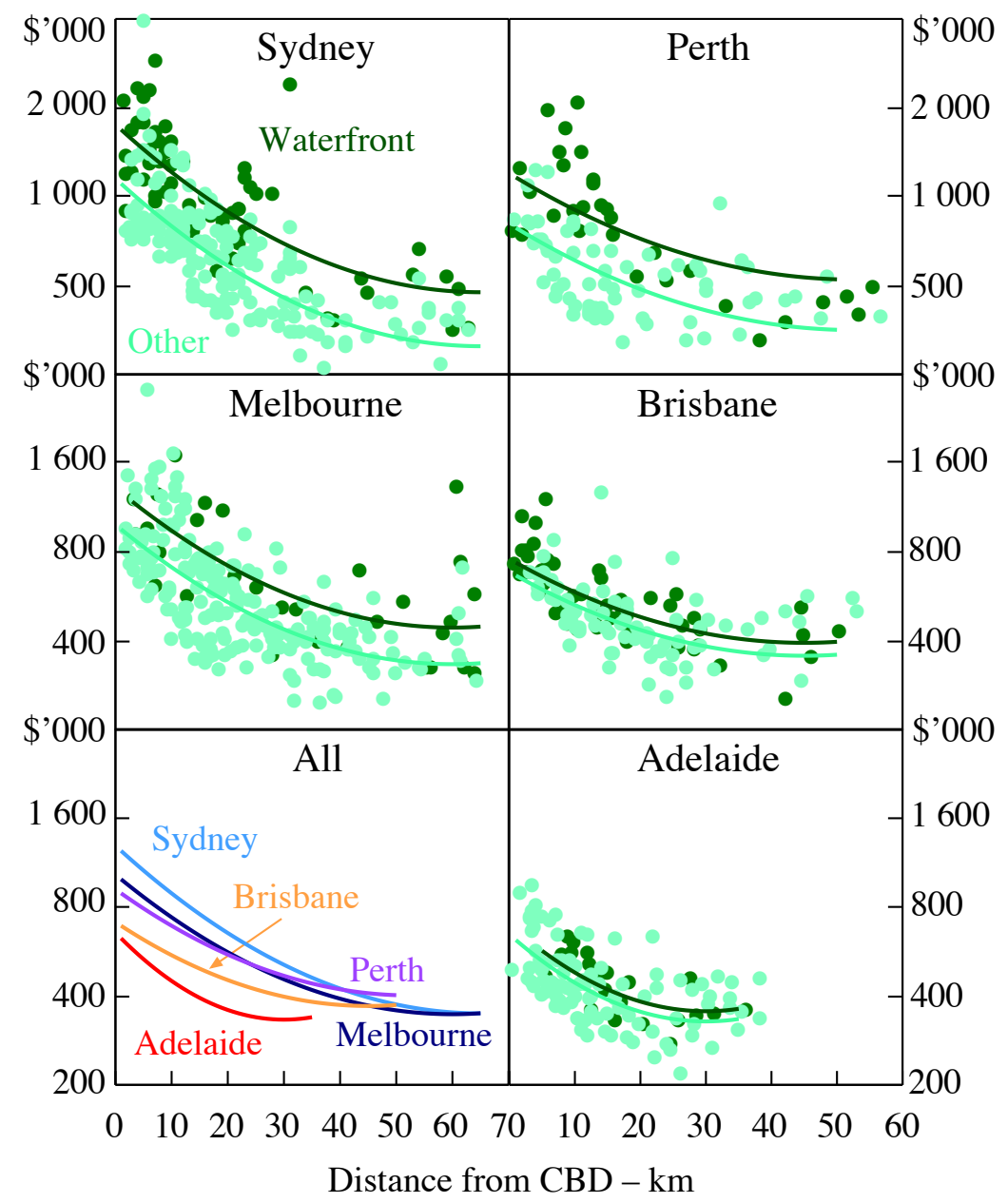

Source: authors' calculations based on data from RP Data-Rismark

The bottom left panel of Figure 10 compares the fitted price lines for each of the five cities, with the line for each city being a weighted average of the waterfront and non-waterfront lines. The data show that prices tend to be highest in Sydney and Melbourne, the two largest cities in terms of population, and lowest in Adelaide which is the smallest city of this group. This is consistent with the model of Section 2, according to which - holding incomes, transportation costs and other factors constant - prices will be higher in cities with larger populations. While it is hard to be categorical, it appears that the slope of the price/distance relationship is less steep in the data than in the theoretical models, which might reflect employment opportunities in these cities being less monocentric than is assumed in the models. 
We also find evidence that prices have grown more rapidly in suburbs closer to the city centres as populations (and incomes and borrowing power) have risen. Table 1 shows the results of regressions of the growth in postcode-level median prices on distance to the $\mathrm{CBD}$ and a waterfront dummy over periods ranging from 17 years (Adelaide) to 29 years (Melbourne). ${ }^{13}$ As in Richards (2008), we find that suburbs closer to the CBD have generally seen higher rates of price growth. Proximity to the water has also become more valued in many cases.

\begin{tabular}{|c|c|c|c|c|c|c|}
\hline \multicolumn{7}{|c|}{ Table 1: Housing Price Growth Regressions - Major Cities } \\
\hline & $\begin{array}{c}\text { Starting } \\
\text { year }\end{array}$ & Constant & $\begin{array}{c}\text { Distance } \\
\text { to } \mathrm{CBD}\end{array}$ & Waterfront & $\begin{array}{c}\text { Adjusted } \\
R^{2}\end{array}$ & $\begin{array}{c}\text { Sample } \\
\text { size }\end{array}$ \\
\hline \multicolumn{7}{|c|}{ Houses } \\
\hline Sydney & $1986 / 87$ & $9.4 * * *$ & $-0.39 * * *$ & $0.64 * * *$ & 0.34 & 185 \\
\hline Melbourne & 1980/81 & $10.1 * * *$ & $-0.42 * * *$ & $1.09 * * *$ & 0.40 & 220 \\
\hline Brisbane & $1983 / 84$ & $8.9 * * *$ & $-0.16^{*}$ & $1.03 * * *$ & 0.25 & 89 \\
\hline Perth & 1988/89 & $9.1 * * *$ & -0.03 & $1.00 * * *$ & 0.16 & 82 \\
\hline Adelaide & $1992 / 93$ & $8.2 * * *$ & $-0.23 * * *$ & $0.38 * *$ & 0.11 & 112 \\
\hline \multicolumn{7}{|c|}{ Apartments } \\
\hline Sydney & $1986 / 87$ & $8.4^{* * *}$ & $-0.38 * * *$ & 0.18 & 0.19 & 103 \\
\hline Melbourne & 1980/81 & $9.4 * * *$ & $-0.36 * * *$ & 0.17 & 0.16 & 120 \\
\hline Brisbane & $1983 / 84$ & $7.3 * * *$ & $-0.28 * *$ & 0.32 & 0.09 & 48 \\
\hline Perth & 1988/89 & $8.3 * * *$ & $-0.31 * *$ & $0.58 * *$ & 0.13 & 63 \\
\hline Adelaide & $1992 / 93$ & $7.8 * * *$ & $-0.40 * * *$ & -0.09 & 0.07 & 75 \\
\hline $\begin{array}{ll}\text { Notes: } & * * \\
& \text { an } \\
& \text { pri } \\
& \text { Th } \\
& \text { as: } \\
& \text { sol } \\
\text { Source: } & \text { au }\end{array}$ & \multicolumn{6}{|c|}{$\begin{array}{l}* * *, * * \text { and } * \text { denote statistical significance at the } 1,5 \text { and } 10 \text { per cent levels, respectively. Results from } \\
\text { an OLS regression of annual average percentage growth to } 2009 / 10 \text { in postcode-level house and apartment } \\
\text { prices on a constant, the distance to the CBD, and a dummy variable for whether the suburb is waterfront. } \\
\text { The coefficient on the distance variable represents the difference in average annual percentage point growth } \\
\text { associated with being } 10 \text { kilometres further from the CBD. Given that median price data can be quite noisy, } \\
\text { some of the equations omit a few outlier observations. } \\
\text { authors' calculations based on data from RP Data-Rismark }\end{array}$} \\
\hline
\end{tabular}

We can use the postcode-level housing price data to do preliminary analysis of developments in housing prices outside of the large state capitals as well. To do so, we calculate the average annual growth rate of median prices between 1992/93 and 2009/10 for all postcodes in Australia for which we have more than 10 transactions in both years. The results are shown in Table 2. For houses, we divide city postcodes into those that are waterfront, those that are non-waterfront

13 These, and the results in Table 2, do not control for the possibility of differential rates of quality change, for example the possibility that there has been a greater degree of renovation in particular types of postcodes or systematic differences in the rate of subdivision of existing blocks of land. However, we suspect that the results would be robust to any quality adjustments. 
but relatively close to the $\mathrm{CBD}$, and those that are non-waterfront and further from the CBD. ${ }^{14}$ As shown earlier, we find that prices in cities have grown more in waterfront and inner-city postcodes. We also find that prices have grown by around 1 percentage point faster per year in the capital cities than outside of the capitals. Interestingly, outside of the capital cities, prices in waterfront postcodes have grown more rapidly than in non-waterfront postcodes, just as has occurred inside the cities. In addition, in the subset of postcodes where we can calculate price growth for both houses and apartments, we find that house prices have grown by around 1.2 percentage points per annum faster than for apartment prices.

\section{Table 2: Average Growth in Housing Prices for 1992/93-2009/10}

\section{Average annual price growth}

Per cent

Houses

Capital cities (855)

8.4

Waterfront (217)

8.8

Non-waterfront (638)

8.2

Inner suburbs (213)

9.2

Outer suburbs (425)

Regional (744)

Waterfront (256)

Non-waterfront (488)

7.1

Postcodes with price data for both houses and apartments

Houses (821)

8.1

Apartments (821)

6.9

Memo items

Growth in CPI (including GST)

Growth in housing construction costs

3.7

\begin{tabular}{ll}
\hline Notes: & $\begin{array}{l}\text { The average annual growth rates are calculated as weighted averages of the growth in postcode-level } \\
\text { median prices, with weights based on the geometric mean of the number of transactions in 1992/93 and } \\
\text { 2009/10. Number of postcodes shown in parentheses. }\end{array}$ \\
Source: & authors' calculations based on data from RP Data-Rismark
\end{tabular}

The differences in the rate of price growth identified here are likely to be the result of a large number of factors, some included and others excluded from the model discussed earlier. The fact that prices for houses (which have a relatively larger amount of land per dwelling) have grown faster than prices for apartments is consistent with the run-up in housing prices over recent decades being more

14 For each capital city, the cut-off for non-waterfront to be considered close to the CBD was set to include one-third of these suburbs. 
a reflection of an increase in the price of land (the scarcer factor) rather than the housing structures per se. ${ }^{15}$ The faster growth in prices in the capital cities relative to the growth outside the capitals seems consistent with issues on the supply side (such as those modelled in Section 3) that constrain the construction of new housing being more of a factor in the capital cities. The finding that prices have grown faster in coastal areas than in inland ones is likely to reflect some combination of changes in preferences and the effect of growth in incomes. Finally, the finding that housing prices have grown faster in inner suburbs than in outer ones could be a combination of many factors, including changes in population, incomes and preferences (the latter possibly linked to transport issues), as well as supply-side factors that constrain the increase in the supply of welllocated housing.

\subsection{Housing Density}

Next, we turn to analyse housing density data based on the 2006 Census. As above, the analysis is done at the postcode level. As a measure of medium- and highdensity living, we calculate the proportion of people in the postcode who lived in flats or apartments of three or more stories. ${ }^{16}$

Figure 11 shows scatter plots of the relationship between this measure of housing density and a suburb's distance from the CBD for the five largest state capitals. The panels also show a line capturing the typical level of density at each distance from the CBD, fitted using a kernel density estimate. There is a clear relationship between this measure of housing density and distance from the CBD. Furthermore, while the fitted curves are somewhat dependent upon the precise form of the kernel estimation, it is clear that density close to the CBD was highest in Sydney and

15 Interestingly, data from LPI do not suggest that representative land prices in the 55 Sydney suburbs shown in Figure 9 have grown more rapidly over 1996-2010 than house prices for those suburbs. However, the LPI website notes a number of caveats, including the fact that estimated land values may not be comparable over time.

16 We use this definition, rather than residents per square kilometre, to avoid the problem of obtaining estimates of the amount of urban land for housing in each postcode. In calculating this proportion, we add together those living in separate houses, semi-detached and terrace houses, townhouses, and flats, units or apartments of one or two stories, to compare with those living in flats, units and apartments of three or more stories. We omit six other (typically small) categories of dwellings which are harder to categorise. The analysis includes all postcodes with at least 500 residents. 
Melbourne, the two largest Australian cities, and lowest in Adelaide, the smallest of the five cities. It is also noteworthy that density falls off quite quickly: at 10 kilometres from the city, the proportion of the population living in apartments of three or more stories in four of the five cities was very small in 2006. Sydney was the exception, with the fitted line indicating that the typical Sydney suburb 10 kilometres from the CBD had around 20 per cent of the population in such apartments.

Figure 11: Postcode-level Housing Density - 2006 Proportion of population in dwellings of three or more stories

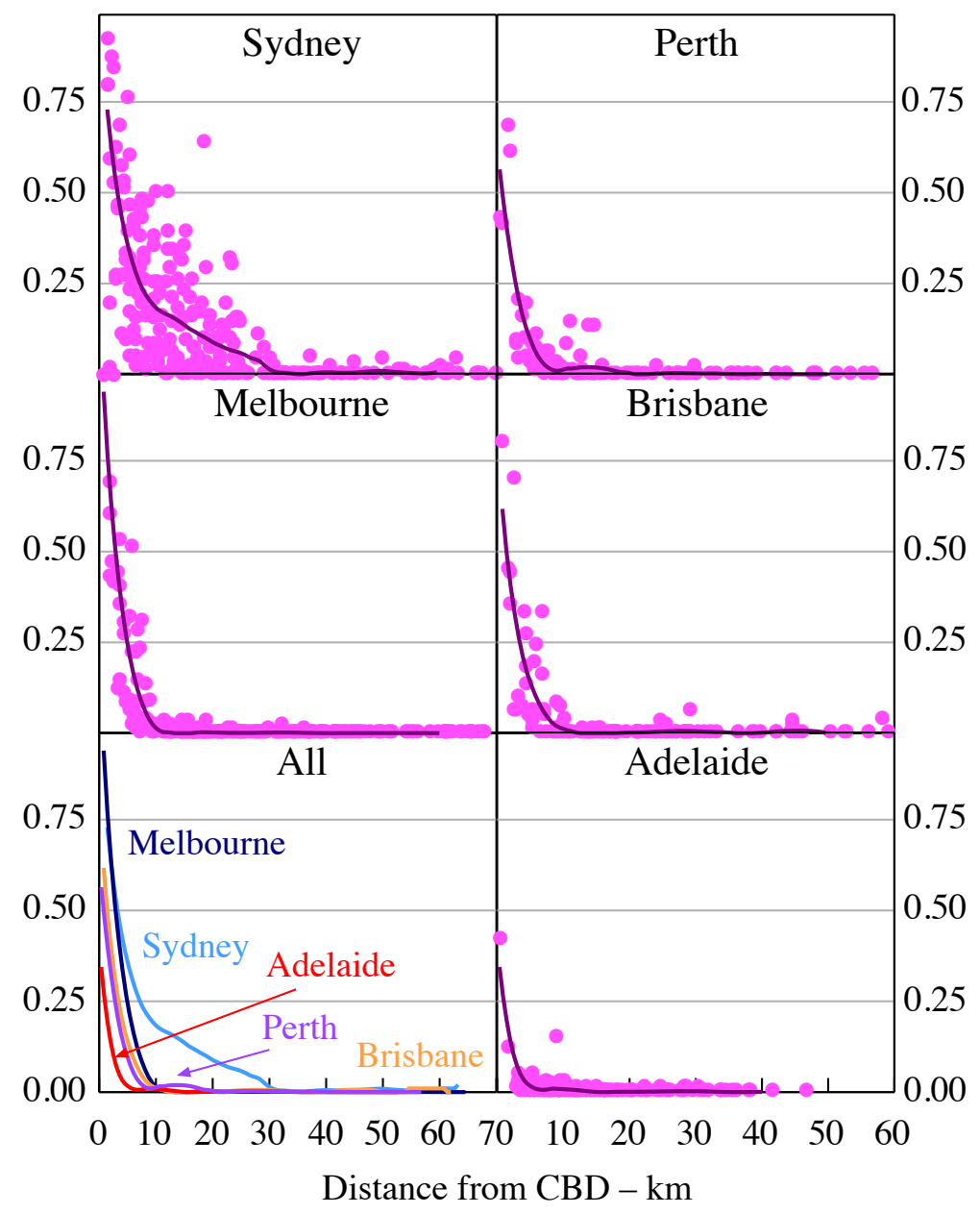

Source: authors' calculations based on data from ABS and RP Data-Rismark

However, the results also indicate significant variation in density in inner- and middle-ring suburbs, with some suburbs close to the CBD with very low density: development plans on council websites for these suburbs typically show relatively 
little land zoned for medium- and high-density use. In contrast, some middlering suburbs have significantly higher density, with some of these being public transport hubs or satellite business districts.

A comparison of housing structure in the 1996 and 2006 censuses provides information on how the structure of the housing stock has evolved and where population growth has occurred. Using data for census areas rather than postcodes, we first divide the census districts within the five largest cities into four groups (referred to as the inner, inner-mid, outer-mid, and outer suburbs), based on their approximate distance from the CBD. Each of the four groups contained approximately the same number of residents in 1996. We calculate how the structure of the housing stock changed for the four groups between 1996 and 2006 using the same metric as in the previous exercise, by comparing the proportion of the dwelling stock that are apartments of three stories or more.

The data, shown in Figure 12, indicate that in Sydney, Melbourne and Brisbane there was a material increase in the proportion of medium- and high-density dwellings in the inner suburbs, with increases of 4-5 percentage points. In Perth and Adelaide the initial proportion of apartments was much smaller, and the increase has also been smaller, at around 1 percentage point. Outside of the inner suburbs, there were mostly only quite small changes in the share of medium- and high-density housing. The exception was Sydney, where the proportion of such dwellings rose by about 2 percentage points in each of the 'inner-mid' and 'outermid' suburbs.

An alternative perspective can be gained from looking at growth in the overall number of dwellings in the different areas of these five cities. Figure 13 shows this growth between 1996 and 2006. The data indicate that growth in the number of dwellings has been strongest in the outermost suburbs in all five cities. Overall growth in the number of dwellings in the outer suburbs of the five cities was 24 per cent, 14 per cent in the 'outer-mid' suburbs, and around 8-9 per cent in the inner and 'inner-mid' suburbs. Together, the results in Figures 12 and 13 suggest that a shift towards high-density housing has been occurring in Australia's cities, especially in the three largest cities, although growth in the housing stock has clearly been strongest towards the fringes of the cities. ${ }^{17}$

17 These data are for the period to 2006. It is likely that the 2011 Census will show some changes, for example, a relatively low rate of greenfield construction on Sydney's fringe. 
Figure 12: Housing Density Over Time

Proportion of all dwellings that were three or more stories

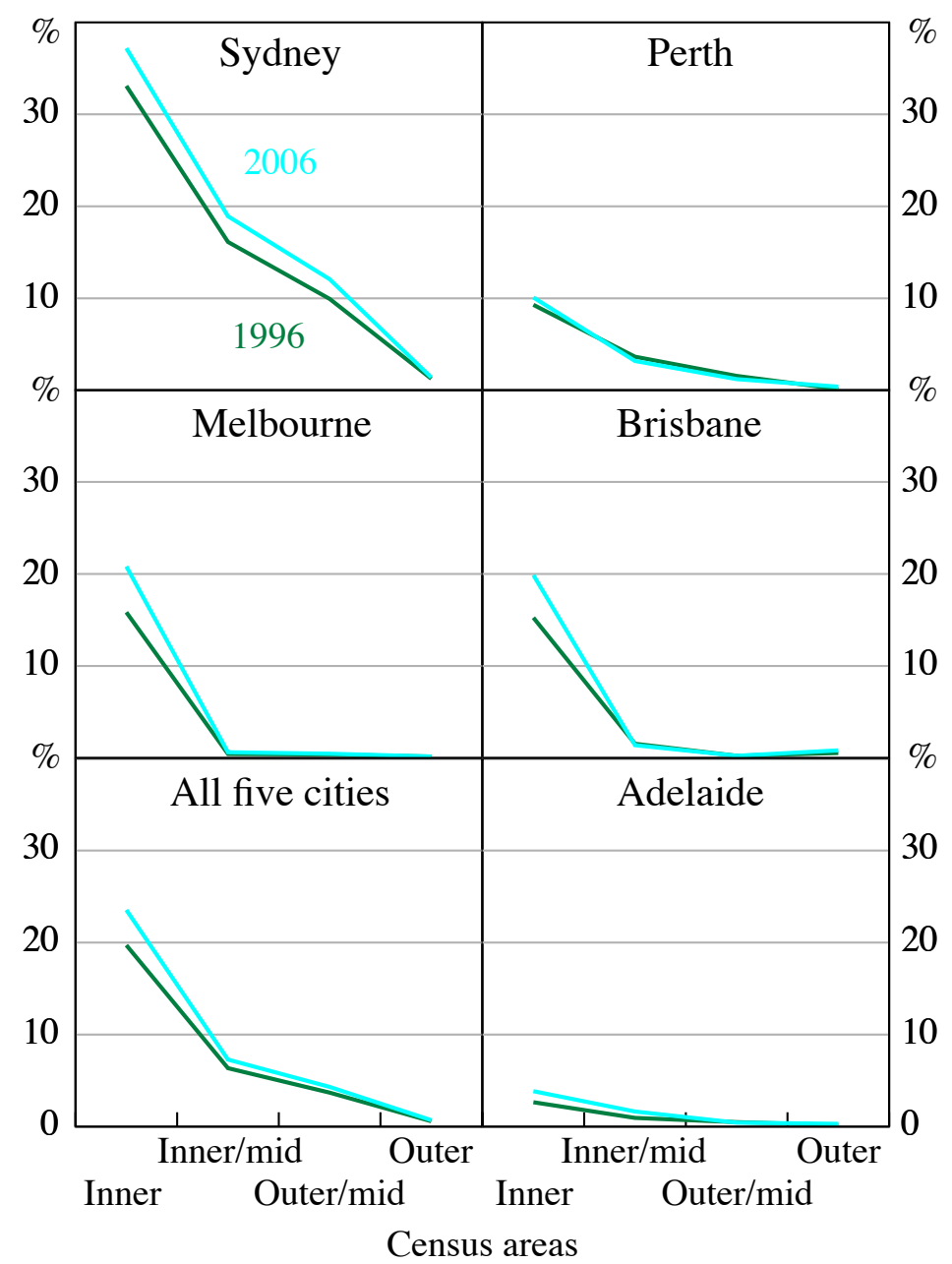

Source: authors' calculations based on data from ABS and RP Data-Rismark

We can also compare the density of the five largest Australian cities with large cities in other developed economies, with data shown in Figure 14. The measure of density here is the ratio of population to urban area, and the other cities are a sample of thirty-three cities in Europe and North America with populations of between 0.8 million and 6 million, selected to be broadly comparable in size to the five Australian cities with populations between 1.0 million and 4.3 million in 2006. ${ }^{18}$

18 Data are from a range of sources, including from Infrastructure Australia, and are mostly for around 2006. Definitions of cities are for broader metropolitan regions and for urban land, consistent with the methodology suggested by Mees (2009). We have also obtained very similar results for a larger sample of 112 cities of comparable size in advanced economies in Asia, Australia, Europe and North America from the 2011 Demographia database. 
Figure 13: Growth in Number of Dwellings by Location

1996-2006

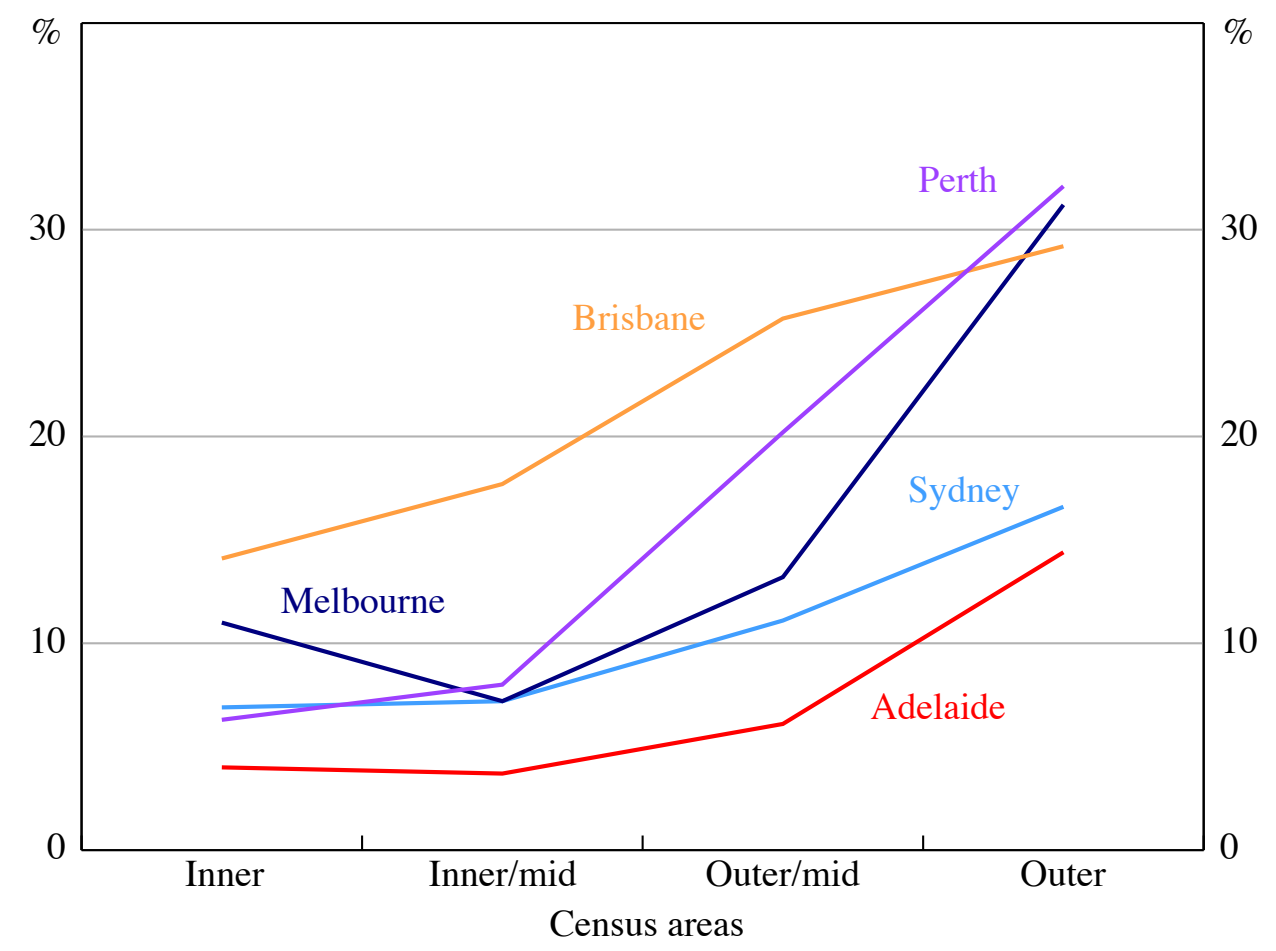

Source: authors' calculations based on data from ABS and RP Data-Rismark

Figure 14: Density and Population of International Cities

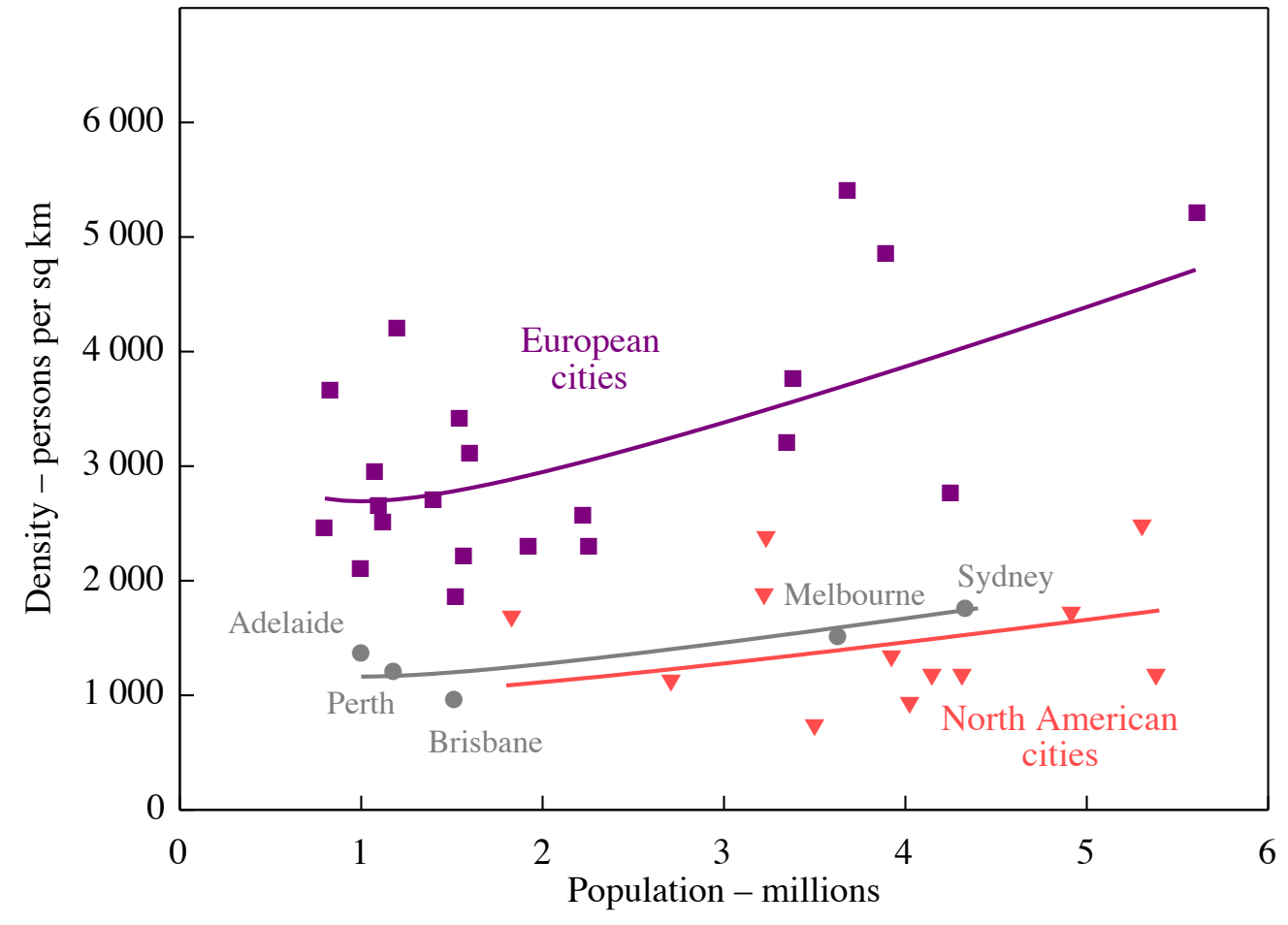


We regress the $\log$ of density (LDen) on the square of the log of population (LPopsq), with the squared term allowing for apparent nonlinearity in the relationship. Given that the data clearly indicate that North American cities are less dense than European ones, we include a dummy variable for North American (NorthAm) cities, in addition to the dummy variable for the Australian (Aust) cities. The estimated relationships for the three groups of cities are shown in Figure 14 and the equation is given below (with standard errors in parentheses):

$$
\text { LDen }=\underset{(0.08)}{7.90}+\underset{(0.06)}{0.16} \text { LPopsq }-\begin{gathered}
0.84 \\
(0.15)
\end{gathered} \text { Aust }-\begin{gathered}
0.97 \\
(0.13)
\end{gathered} \text { NorthAm }
$$

The coefficient on the population is significant and takes the expected positive sign. ${ }^{19}$ The finding that cities with larger populations tend to have higher density is not surprising and is consistent with the model discussed above. The results also indicate that, controlling for population, the density of US cities is significantly lower than European cities. The density of Australian cities is also significantly less than that of European cities, with the ( $\log$ ) regression coefficient suggesting density of around 43 per cent of European cities (and not significantly different to US cities). That is, notwithstanding the increase in housing density shown in Figures 12 and 13, the density of Australian cities in 2006 was still quite low relative to European cities, although broadly similar to US cities.

\subsection{Land Use Policies}

Unfortunately, there is little systematic quantitative data on land zoning or land usage in Australia's major cities, in part because some cities either do not have (or are only now moving towards) standardisation in zoning definitions across local government areas. However, in the case of Perth, the Department of Planning makes available some high-quality data on the location and zoning of land zoned for residential usage. This included a standardised measure of permitted housing density, namely the R-Code which represents the maximum number of dwellings per hectare allowed under the zoning: for example, the R20 code specifies no more than 20 dwellings per hectare, that is a minimum block size of 500 square metres (sqm) per dwelling. Codes from R5 to R25 (minimum block size of 2000 sqm to

19 A variable for whether is a city is coastal was also tested. While it took the expected positive sign (i.e. land constraints should result in greater density), it was insignificant. 
$400 \mathrm{sqm}$ ) are classified low density and can be thought of as being for freestanding, single-family houses; codes from R30 to R60 (from 333 sqm to 167 sqm of land per dwelling) are classified as medium density and broadly correspond to townhouses; and codes of R80 or above (equivalent to less than 125 sqm land per dwelling) are classified higher density and correspond to apartments.

Figure 15 provides an overview of the Perth zoning data as of early 2011, and the relationship between zoning and distance from the $\mathrm{CBD}$, with distance broken into 2 kilometre bands. The figure shows the proportion of land zoned low, medium, and high density at each distance. ${ }^{20}$ The data indicate that around 86 per cent of residential land in Perth is zoned for low density/single-family houses, with around 13 per cent for medium density/townhouses and 1 per cent for high density/apartments. Not surprisingly, the land that is zoned for medium- and highdensity housing tends to be located closer to the CBD. However, even within 10 kilometres of the city, the majority of land is reserved for freestanding houses, with around 67 per cent of land zoned low density, and only 3 per cent of land zoned for high-density use.

The data for Perth, together with a visual examination of zoning maps (where available) for local government areas in the other large cities, appear broadly consistent with the relatively low density of Australian cities illustrated in Figure 14. By themselves, however, these data say nothing about whether existing zoning may be a constraint on the development of the city along the lines of the effects illustrated in Figure 4. To draw conclusions on this issue would require evidence regarding whether land zoned for medium- and high-density housing use is or is not being used for this purpose, as well as evidence on land values, and whether land is valued significantly more highly when its zoning allows greater flexibility of usage and higher density development. There is, however, very limited hard evidence (as opposed to anecdotal) on these questions.

20 The data are for the greater Perth area, specifically the Perth Metropolitan and Peel regions. The analysis of the raw data required some judgement. For example, some land in the database had an R-Code, although its zoned usage was something other than residential: in these cases we examined the relevant local planning scheme and included it in the analysis if residential was one of the allowed uses under the designated zoning. In other cases, land was zoned with multiple R-Codes, for example R20/40/80, which indicates that its primary use is for the lower density usage, but that development approval for a higher density use could be granted if certain conditions were met: in such cases we allocated it predominantly to the lower density usage, although the data shown in Figure 15 are not especially sensitive to this assumption. 


\section{Figure 15: Perth - Zoning of Residential Land} Early 2011

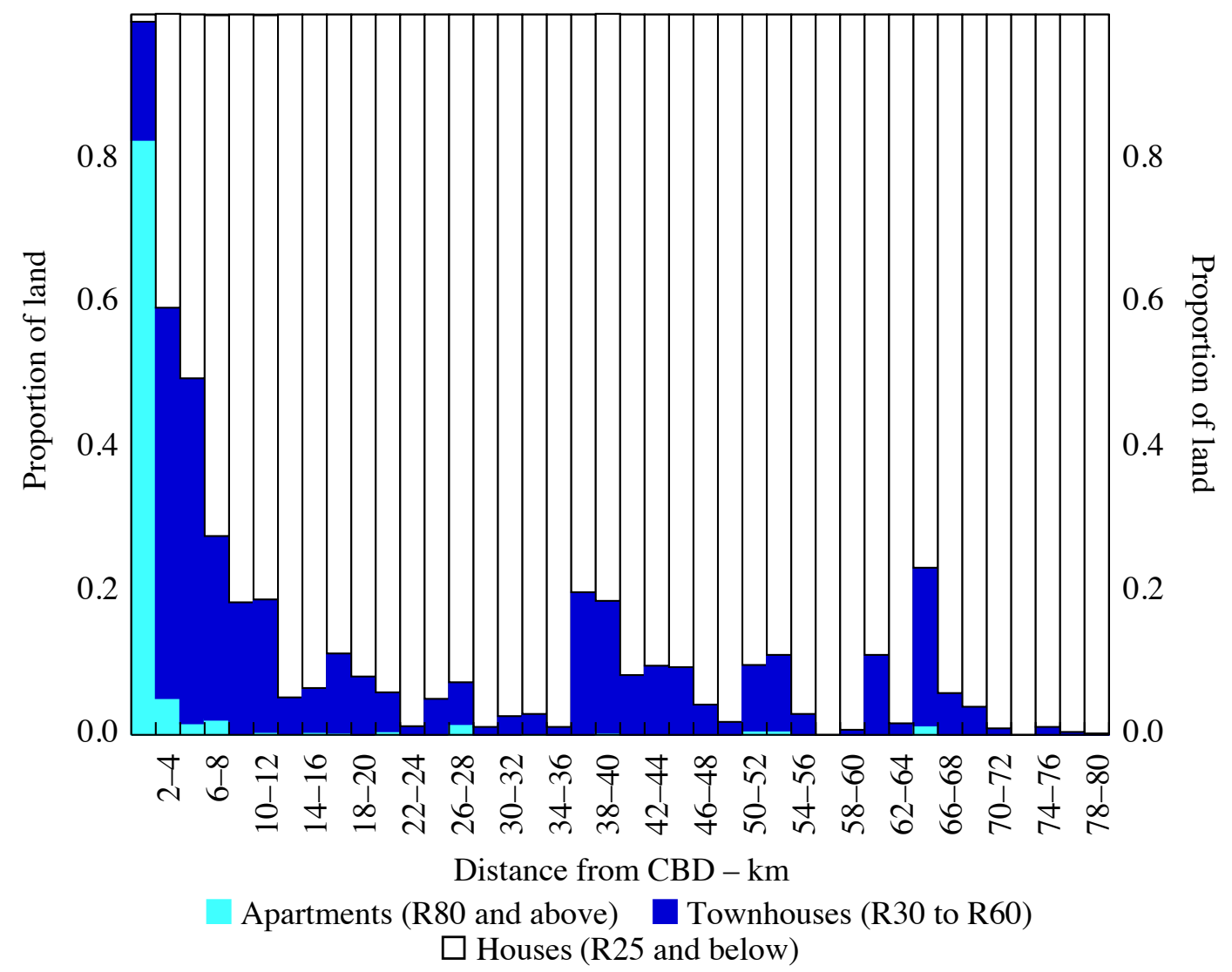

Source: authors' calculations based on data from Department of Planning

However, in the case of land at the city fringe, there is evidence from Melbourne of a very significant uplift in prices when land is included (or is considered for inclusion) in the urban growth boundary (UGB). Research by Charter Keck Cramer suggests an increase in value of $\$ 300000$ to $\$ 400000$ per hectare for land in the UGB, compared with an underlying value of $\$ 15000$ to $\$ 35000$ per hectare for farming land outside Melbourne. ${ }^{21}$

In the case of land within the city, there is some systematic evidence in a report by the Centre for International Economics (2011) which compares land valuations for blocks of land that are quite comparable in size and location, but differing in zoning. The median valuation differential across 43 Sydney local governments

21 See GAIC Information Sheet, available at <http://www.gaa.vic.gov.au/gaic/>. Price differences in the case of London's fringe are far larger: Cheshire and Sheppard (2005) suggest differences of millions of pounds per hectare. 
suggests a premium of around 15 per cent for land with medium-density zoning. ${ }^{22}$ In addition, there are many anecdotes of very large increases in property values associated with changes in zoning. ${ }^{23}$

Finally, there is also some evidence on the broader question of how well the current dwelling stock in Australia's two largest cities matches the preferences of households. Kelly, Weidmann and Walsh (2011) study the surveyed housing preferences of Sydney and Melbourne households, in terms of location, type and size, taking into account incomes and the cost of various forms of housing. Based on this, the authors calculate the structure of the housing stock that would be implied by household preferences and compare it with the structure of the existing housing stock. Their analysis in this regard suggests that the population would prefer less detached housing in both cities, and more medium- and high-density housing, particularly semi-detached housing and apartments of four stories or more. The authors note that some mismatch between the existing and desired housing stock is always to be expected, given the long-lived nature of the housing stock. However, they note a series of supply-side factors - including many corresponding to the type of factors modelled in Section 3 - that have constrained housing construction. For example, in Sydney, they point to complexity of the planning process for infill development, and infrastructure charges and the price and supply of land on the city fringe. In the case of Melbourne, they note that there have been significant amounts of greenfield development on the fringe and of new inner-city high-rise apartments, but that development in established areas (outside the inner city) has been constrained by planning complexity and high construction costs for apartments.

22 There are, however, a few reasons to think that this could be an underestimate, in part due to imprecision in land prices used (based on state government valuations rather than market transactions) and imperfect matching of land (while blocks of land used in comparisons were within 100 metres of each other, it seems plausible that land zoned for apartments would be more likely to be closer to busier roads). In addition, if the typical zoning for apartments does not allow the type of development that that would result in an unconstrained market then the premium would also be understated relative to the unconstrained situation.

23 For example, a recent article in The Australian Financial Review suggested an uplift of nearly 400 per cent for three blocks of land on Sydney's lower north shore following a rezoning to permit the construction of apartments (see Hurley (2011)). The article suggests three blocks in St Leonards were each valued at about $\$ 1$ million with low-density residential zoning, but with rezoning to 'mixed use' were sold together for $\$ 14.5$ million. 
Together, this evidence suggests that zoning and other planning rules are having a material effect on the use of land, and by implication must also be having some effect on the cost of housing, as per the results in Section 3. While the direction of these effects, and of the other policies modelled in Section 3, are fairly clear, it is difficult to make precise judgments of their magnitude. Indeed, there appears to be little empirical evidence from academics or planners in this area. ${ }^{24}$ Given the importance of housing in household budgets and in broader social outcomes, this suggests significant scope for further data collection and empirical work on the pricing, usage and zoning of land in our major cities. There is also scope for studies on the extent to which policies on the supply-side of the housing market could be having greater effects on housing prices as the populations of our major cities have grown. Barker (2004), Bertaud and Malpezzi (2003) and others have argued that data on housing affordability, as well as on land zoning and land usage, should be important inputs into policies surrounding the planning process.

\section{Conclusion}

In this paper we use a simple model that highlights some long-run influences on the supply and demand for urban housing. While the model abstracts from some aspects of reality, we show in Section 4 that it is consistent with many of the key patterns observed in Australia's large cities.

The model highlights the importance of transport infrastructure. While we do not model the financing of such infrastructure, the model points to the potentially significant effects of transport systems on households. In particular, in cities with better transport infrastructure it is more feasible to live further from the city, where land and housing prices are lower and dwelling sizes can be larger. It is noteworthy that reports on the development process for Australian cities have pointed to transport problems being a major issue for development at the city fringe (e.g. Applied Economics (2010)).

The analysis also highlights the effect of land usage policies on housing density and prices. We show that zoning limits on the amount of housing built close to the CBD imply that more of the population lives in middle and outer rings,

24 For example, a search in EconLit with the terms 'Australia', 'land prices' and 'zoning' found no articles nor did 'zoning + housing + prices + Australia', while 'zoning + Australia' gave two marginally relevant results. In contrast, 'zoning + United + States' gave 34 results. 
increasing the overall footprint of the city and resulting in higher housing prices. These effects can be expected to become more pronounced as the population of cities increase. In particular, as population grows and land prices increase, the expected response would be for cities to become denser and for land to be used more intensively. However, any fixed set of zoning restrictions will slow this adjustment. ${ }^{25}$ While the model predicts city-wide benefits - in terms of more affordable and better-located housing (and larger average dwelling sizes) - from less restrictive zoning, it is noteworthy that existing residents often oppose the easing of zoning restrictions in their own neighbourhoods. This highlights an important point: there is a trade-off between density and housing prices. ${ }^{26}$

The model shows that policies associated with the development process that act as a friction on the supply of new housing result in higher housing prices for consumers and a reduction in the supply of housing. In the model, which assumes a fixed number of people per household, this is reflected in smaller dwelling sizes, but one can also think of these policies as resulting in an increase in the average number of people living in dwellings of any given size.

While demand-side factors, especially changes in the cost and availability of finance, have clearly been very important in explaining developments in the Australian housing market over the past two decades, our results lend support to other work pointing to the role of structural factors in influencing housing market outcomes. There is a growing body of international evidence on the role of supply-side constraints in limiting construction and driving up prices: for example, see Gitelman and Otto (2010) for Australia; Grimes (2007) for New Zealand; Barker (2004) for the United Kingdom; Green, Malpezzi and Mayo (2005), Glaeser et al (2005a), Glaeser, Gyourko and Saks (2005b) and Saiz (2010) for the United States; and Andrews, Caldera Sánchez and Johansson (2011) for a large sample of OECD economies. The evidence for Australia presented in Section 4 is also consistent with various supply-side aspects boosting the cost of housing,

25 In this regard, a recent report by the Productivity Commission (2011, p xviii) calls for 'broad and simple land use controls to: reduce red tape, enhance competition, help free up urban land for a range of uses and give a greater role to the market in determining what these uses should be'. More broadly, the report suggests that planning systems in Australian cities suffer from 'objectives overload', which has been increasing over time.

26 See NHSC (2010, p 123) for a discussion of some options for stimulating higher density and infill developments in our cities. 
although these findings are tentative given the paucity of data on land prices and zoning, and on the relationship between these variables.

Finally, we note that the effects on the cost of housing of any given set of development, land use and transport policies will tend to be more pronounced as the population grows. Arrangements which might have been considered broadly appropriate at some point in the past are likely to have more pronounced effects as the population expands. This suggests that any set of policies that were thought optimal at one time, in terms of the trade-offs, might no longer be so as the population grows. 


\section{Appendix A: Model Calibration}

We solve the model using Mathematica. The code is available on request.

\section{Notation}

$x$ is the location as measured by distance from the center of the city, which is $x=0 ; \bar{x}$ is the distance to the urban-rural boundary; $t>0$ is the commuting cost parameter; $y$ is an exogenously determined annual wage; $q$ is the consumption of housing measured in floor space per dwelling; $p$ is the price per square metre of housing ${ }^{27}$; $c$ is the consumption of a bundle of other goods with its price normalised to unity; $h$ is housing production measured in housing floor space per unit of land; $l$ is the input of land into the production of housing; $K$ is the input of capital into the production of housing; $S$ is the capital-land ratio $K / l ; r$ is the rental price of land; $i$ is the exogenously determined rental rate on capital; $L$ is the city's population.

\section{Demand for housing}

The representative individual maximises utility, $v(c, q)$, by consuming housing and a bundle of other goods, subject to the budget constraint, $p q+c=y-t x$. The optimality conditions of the households problem are

$$
\frac{v_{q}(y-t x-p q, q)}{v_{c}(y-t x-p q, q)}=p
$$

and

$$
v(y-t x-p q, q)=u
$$

Equations (A1) and (A2) give solutions for $q$ and $p$ as functions of $y, t, u$ and $x$.

\section{Supply of housing}

At a particular location $x$, a housing producer generates profit $l(p h(S)-r-i S)$. The first order conditions from profit maximization are given by

$$
p h^{\prime}(S)=i
$$

27 The analysis is of the absentee-owner version of the model, whereby households implicitly pay rent to landlords outside the city. See Pines and Sadka (1986) for a model where land is internally owned. 
and

$$
r=p h(S)-i S
$$

Equations (A3) and (A4) give solutions for $S$ and $r$.

\section{Equilibrium}

The equilibrium conditions determine the level of welfare, $u$, and the city boundary, $\bar{x}$. They require that the rental price of land at $\bar{x}$ equals the agricultural rent, $r_{a}$, and that given population density, $D \equiv \frac{h}{q}$, the population fits inside $\bar{x}$. These are

$$
r(\bar{x}, u)=r_{a}
$$

and

$$
\int_{0}^{\bar{x}} \theta x \frac{h(S(x, u))}{q(x, u)} d x=L
$$

Given Equations (A1) to (A4), Equations (A5) and (A6) simultaneously determine the equilibrium values of $\bar{x}$ and $u$.

\section{FAR restriction}

A FAR restriction imposes an upper bound on the floor space of housing produced per unit of land. Following Bertaud and Brueckner (2005), such restriction takes the form, $h(S) \leq \hat{h}$. Because $h$ falls with distance, the constraint will bind closer to the centre and will not bind further out. If $\hat{x}$ denotes the location where the FAR restriction becomes binding, then the equilibrium conditions are given by

$$
\begin{gathered}
r(\bar{x}, u)=r_{a} \\
h(S(\hat{x}, u))=\hat{h} \\
\int_{0}^{\hat{x}} \theta x \frac{\hat{h}}{q(x, u)} d x+\int_{\hat{x}}^{\bar{x}} \theta x \frac{h(S(x, u))}{q(x, u)} d x=L
\end{gathered}
$$

The system of Equations (A7)-(A9) determine the equilibrium values of $\hat{x}, \bar{x}$, and $u$. 


\section{Calibration and functional forms}

Following Bertaud and Brueckner (2005), we assume for tractability CobbDouglas utility and production functions of the form, $v(c, q)=c^{1-\alpha} q^{\alpha}$ and $h(S)=$ $g S^{\beta}$. Table A1 below summarises the benchmark calibration. In 2007-2008, mean household disposable income per week was \$1 366 (Household Income and Income Distribution, Australia, 2007-08, ABS Cat No 6523.0, Appendix 3, Table A5.) This implies an annual income of $\$ 71$ 032, which we round to $\$ 70000$. Based on 2005/06 data (Year Book Australia 2008, ABS Cat No 1301.0), average weekly housing costs for all household types was $\$ 185$, which implies an $\alpha$ of about $0.14 .^{28}$ We assume the city's population is 2 million, living in 800000 households of an average size of 2.5 persons per household.

\begin{tabular}{llr}
\hline & \multicolumn{1}{c}{ Table A1: Calibration } \\
\hline Parameter & Description & Value \\
\hline$y$ & Income $(\$ /$ year) & 70000 \\
$\alpha$ & Utility function - expenditure share on housing & 0.14 \\
$\beta$ & Housing production function parameter on structures & 0.60 \\
$g$ & Scaling on the housing production function & 0.0005 \\
$i$ & Price of capital & 1 \\
$t$ & Transport costs $(\$ /$ year $/ \mathrm{km})$ & 600 \\
$\theta$ & Radians available for construction & 3 \\
$r_{a}$ & Agricultural land rent $\left(\$ / \mathrm{km}^{2} /\right.$ year $)$ & 45000 \\
$L$ & Population & 2000000 \\
\hline
\end{tabular}

Agricultural land rent is a broad average of the rental prices of coastal grazing and wheat properties using New South Wales land data, assuming a 10 per cent rate of return (see $<$ http://www.lpma.nsw.gov.au/valuation/nsw_land_values $>$ ).

To estimate transport costs, we follow Bertaud and Brueckner (2005) methodology. We assume 1.35 workers per households and 40 hours work per week so that the hourly wage is $\$ 25.30$. Assuming the commute time is valued at 60 per cent of the wage rate, and traffic moves at $50 \mathrm{~km} /$ hour the time cost of commuting is $\$ 0.30 / \mathrm{km}$ per worker. According to the NRMA, in 2008 the

28 The share of expenditure on housing is estimated to be somewhat higher in the 2009/10 Household Expenditure Survey, which became available after this paper was finalised. While different assumptions for this parameter, or for average household income, will result in slightly quantitative results, the broad economic relationships identified in the calibration exercise are all robust to changes in these parameters. 
operating cost of a medium-sized car is about $\$ 0.67 / \mathrm{km}$. Together, this means the transport cost is $\$ 0.97 / \mathrm{km}$ per worker. Grossing up by the number of workers per household (1.35) and the number of trips per year (240 work days per year), and then multiplying by two to account for return trips, total commuting cost is $\$ 628$ per year. We round this to $\$ 600$. 


\section{References}

Alonso W (1964), Location and Land Use: Toward a General Theory of Land Rent, Harvard University Press, Cambridge.

Anas A (1990), 'Taste Heterogeneity and Urban Spatial Structure: The Logit Model and Monocentric Theory Reconciled', Journal of Urban Economics, 28(3), pp 318-335.

Anas A, R Arnott and KA Small (1998), 'Urban Spatial Structure', Journal of Economic Literature, 36(3), pp 1426-1464.

Andrews D, A Caldera Sánchez and Å Johansson (2011), 'Housing Markets and Structural Policies in OECD Countries', OECD Economics Department Working Paper No 836.

Applied Economics (2010), 'Residential Building Activity in Sydney: An Overview and Seven Case Studies', Consultant report prepared for NSW Treasury.

Arnott RJ and JG MacKinnon (1977), 'Measuring the Costs of Height Restrictions with a General Equilibrium Model', Regional Science and Urban Economics, 7(4), pp 359-375.

Aura S and T Davidoff (2008), 'Supply Constraints and Housing Prices', Economics Letters, 99(2), pp 275-277.

Barker K (2004), Delivering Stability: Securing Our Future Housing Needs, Barker Review of Housing Supply - Final Report - Recommendations, HMSO, Norwich.

Battellino R (2009), 'Housing and the Economy', RBA Bulletin, December, pp 35-42.

Bertaud A and JK Brueckner (2005), 'Analyzing Building-Height Restrictions: Predicted Impacts and Welfare Costs', Regional Science and Urban Economics, 35(2), pp 109-125.

Bertaud A and S Malpezzi (2003), 'The Spatial Distribution of Population in 48 World Cities: Implications for Economies in Transition', University of Wisconsin, Center for Urban Land Economics Research Working Paper No 03-05. 
Brueckner JK (1983), 'The Economics of Urban Yard Space: An "ImplicitMarket" Model for Housing Attributes', Journal of Urban Economics, 13(2), pp 216-234.

Brueckner JK (1987), 'The Structure of Urban Equilibria: A Unified Treatment of the Muth-Mills Model', in ES Mills (ed), Handbook of Regional and Urban Economics, Volume 2: Urban Economcs, Elsevier Science, Amsterdam, pp 821-845.

Brueckner JK (2007), 'Government Land-Use Interventions: An Economic Analysis', Paper presented at the World Bank Fourth Urban Research Symposium on 'Urban Land Use and Land Markets', Washington DC, 14-16 May.

Caplin A, C Joye, P Butt, E Glaeser and M Kuczynski (2003), 'Innovative Approaches to Reducing the Costs of Home Ownership', A report commissioned by the Menzies Research Centre for the Prime Minister's Home Ownership Task Force, Volume 1.

Centre for International Economics (2011), 'Investment in Transport in New South Wales: Economic Impacts', Report prepared for Property Council of Australia.

Cheshire P and S Sheppard (2005), 'The Introduction of Price Signals into Land Use Planning Decision-Making: A Proposal', LSE Research Online. Available at $<$ http://eprints.lse.ac.uk/archive/00000568 $>$.

Ellis L (2006), 'Housing and Housing Finance: The View from Australia and Beyond', RBA Research Discussion Paper No 2006-12.

Evans AW (1999), 'The Land Market and Goverment Intervention', in P Cheshire and ES Mills (eds), Handbook of Regional and Urban Economics, Volume 3: Applied Urban Economcs, Elsevier Science, Amsterdam, pp 1637-1669.

Evans AW (2004), Economics and Land Use Planning, Real Estate Issues Series, Blackwell Publishing Ltd, Oxford.

Gitelman E and G Otto (2010), 'Supply Elasticity in the Sydney Housing Market', unpublished paper, The University of New South Wales, School of Economics. Available at $<$ http://members.optusnet.com.au/ g.otto/Housing_Supply_Dec_10.pdf $>$. 
Glaeser EL, J Gyourko and RE Saks (2005a), 'Why Have Housing Prices Gone Up?', The American Economic Review, 95(2), pp 329-333.

Glaeser EL, J Gyourko and RE Saks (2005b), 'Why is Manhattan So Expensive? Regulation and the Rise in Housing Prices', The Journal of Law and Economics, 48(2), pp 331-369.

Green RK, S Malpezzi and SK Mayo (2005), 'Metropolitan-Specific Estimates of the Price Elasticity of Supply of Housing, and their Sources', The American Economic Review, 95(2), pp 334-339.

Grimes A (2007), 'Impacts of Land Availability, Housing Supply and Planning Infrastructure on New Zealand House Prices', Paper presented at The Treasury and Reserve Bank of New Zealand Workshop on 'The Business Cycle, Housing and the Role of Policy', Wellington, 10-11 December.

Gurran N (2007), Australian Urban Land Use Planning: Introducing Statutory Planning Practice in New South Wales, Sydney University Press, Sydney.

Gurran N, K Ruming and B Randolph (2009), Counting the Costs: Planning Requirements, Infrastructure Contributions, and Residential Development in Australia, AHURI Final Report No 140, Australian Housing and Urban Research Institute, Melbourne.

Henderson V and A Mitra (1996), 'The New Urban Landscape: Developers and Edge Cities', Regional Science \& Urban Economics, 26(6), pp 613-643.

Hill RJ and D Melser (2007), 'The Anatomy of a Housing Boom: Sydney 20012003', The University of New South Wales, School of Economics Discussion Paper No 2007/01.

Hurley B (2011), 'Smart Owners Reap Windfall', The Australian Financial Review, 9 March, p 3.

Kelly J-F, B Weidmann and M Walsh (2011), 'The Housing We'd Choose', Grattan Institute Report No 2011-5.

Mees P (2009), 'How Dense are We? Another Look at Urban Density and Transport Patterns in Australia, Canada and the USA', Road and Transport Research, 18(4), pp 58-67. 
Mills ES (1967), 'An Aggregative Model of Resource Allocation in a Metropolitan Area', The American Economic Review, Papers and Proceedings, 57(2), pp 197-210.

Muth RF (1969), Cities and Housing: The Spatial Pattern of Urban Residential Land Use, Third Series: Studies in Business and Society, University of Chicago Press, Chicago.

Newman P, J Kenworthy and P Vintila (1992), Housing, Transport and Urban Form, The National Housing Strategy Background Papers No 15, Australian Government Publishing Service, Canberra.

NHSC (National Housing Supply Council) (2010), 2nd State of Supply Report, Department of Families, Housing, Community Services and Indigenous Affairs, Canberra.

Pines D and E Sadka (1986), 'Comparative Statics Analysis of a Fully Closed City’, Journal of Urban Economics, 20(1), pp 1-20.

Productivity Commission (2011), Performance Benchmarking of Australian Business Regulation: Planning, Zoning and Development Assessments, Volume 1, Research Report, Productivity Commission, Canberra.

Richards AJ (2008), 'Some Observations on the Cost of Housing in Australia', RBA Bulletin, April, pp 26-36.

Saiz A (2010), 'The Geographic Determinants of Housing Supply', The Quarterly Journal of Economics, 125(3), pp 1253-1296.

Spivey C (2008), 'The Mills-Muth Model of Urban Spatial Structure: Surviving the Test of Time?', Urban Studies, 45(2), pp 295-312.

Wheaton WC (1974), 'A Comparative Static Analysis of Urban Spatial Structure', Journal of Economic Theory, 9(2), pp 223-237. 